NBER WORKING PAPER SERIES

\title{
BALANCED AND UNBALANCED GROWTH
}

James E. Rauch

Working Paper No. 4659

\author{
NATIONAL BUREAU OF ECONOMIC RESEARCH \\ 1050 Massachusetts Avenue \\ Cambridge, MA 02138 \\ February 1994
}

I thank Pu Shen for her invaluable research assistance, Andy Levin for his helpful comments, and Rudolf Buitelaar for providing me with data from the files of ECLAC. I am also grateful for research assistance provided by Subir Bose, Brad Kamp, Jaesun Noh, and Rajiv Sarin, and for support from NSF grant \# SES91-21217. Earlier drafts of this paper were presented at seminars at Princeton University, Yale University, the National Bureau of Economic Research Conference on Economic Growth, and the University of Wisconsin, Madison. I am responsible for any errors. This paper is part of NBER's research program in International Trade and Investment. Any opinions expressed are those of the author and not those of the National Bureau of Economic Research. 
NBER Working Paper \#4659

February 1994

\title{
BALANCED AND UNBALANCED GROWTH
}

\begin{abstract}
A mechanism of endogenous growth suitable for investigation of sectoral or regional interaction is developed. It is shown how the high value placed on production linkages by economic historians might be reconciled with the high value placed on openness (often implying lack of linkages) by observers of contemporary less developed countries. When the output of one sector is traded and the output of the other is nontraded, it is shown how the traded goods sector acts as the "engine of growth" in the sense that its profitability of knowledge acquisition primarily determines the steady state aggregate growth rate. It is also shown how sectors or regions interact out of steady state through product, labor, and capital markets, and in particular how if the former interaction dominates the growth of one sector "pulls along" the growth of the other while if the latter two interactions dominate one sector or region booms while the other declines. The paper builds on these results to show why liberalization of foreign trade should lead to a transition from a lower to a higher steady state growth rate and why, during the course of this transition, growth might initially be even slower than before liberalization. On this basis a reinterpretation of the post-1973 economic performance of Chile is offered. A final application to economic integration of previously separate regions or countries shows that the largest growth effects are to be had if one region is allowed to decline and provide a source of cheap labor for the other region.
\end{abstract}

James E. Rauch

Deparment of Economics

University of California, San Diego

La Jolla, CA 92093

and NBER 
This paper addresses several related issues. How does growth in one region or sector of a country stimulate growth in another sector or region? This phenomenon is known in the economic development literature as linkage. If the linkage is severed, what happens to the sector or region that served as the "engine of growth," and what happens to the sector or region that was being pulled along? How does this sectoral interaction work to determine the country's aggregate growth rate?

In the model I propose there are two sectors, which can in specific historical circumstances correspond to two regions. Sector $\mathrm{T}$ is a traded goods sector and sector $\mathrm{N}$ is a nontraded goods sector. Goods may be nontraded because of transportation costs (e.g., services, perishable agricultural products, poor internal transport to interior regions) or because of government policy (high barriers to international trade). 1 The country is assumed to be small relative to the world economy so that the price of traded goods is fixed in international markets. Growth occurs by accumulation of knowledge. Like most small countries (and many large, poor ones) this country does not do any research and development, acquiring all of its new knowledge from abroad instead. I suppose that the country is sufficiently "backward" that we can treat the supply of this new knowledge as inexhaustible.

I suppose that knowledge acquired in one sector is not directly useful in the other. For this reason there is no cause to believe a priori that both sectors will grow at the same rate, i. e., that growth will be "balanced". Sectoral growth rates are nevertheless linked through product, labor, and capital markets. Growth of sector $T$ generates demand for the output of sector $\mathrm{N}$ by increasing consumer income (a "consumption linkage"). ${ }^{2}$ Suppose then that sector $T$ is initially growing faster than sector $N$, causing the relative price of

When nontradeability is due to transportation costs it might be reasonable to think of the area covered by the two sectors of the model as smaller than that of the entire country. In the concluding section of this paper I discuss how my model could be more formally related to the regional economics literature.

2In Rauch (1992) I also cover the case where sector $\mathrm{N}$ output is used as an input by sector $\mathrm{T}$ (a "production linkage"). 
nontraded goods to increase. Since both sectors draw on a common pool of labor, this movement of the terms of trade in favor of sector $\mathrm{N}$ will raise the real wage for sector $\mathrm{T}$ and thus reduce the incentive to invest in more knowledge, slowing growth there, while having the opposite effect in sector $N$. In short, some (perhaps unique) terms of trade will exist that balances growth between the two sectors, and associated with these terms of trade will be a (perhaps unique) steady state rate of growth. ${ }^{3}$

Most empirical studies of this kind of sectoral growth interaction identify the two sectors as agriculture and industry, either of which may play the "leading" role depending on the specific historical situation. The interaction between agriculture and industry is an attractive subject for empirical research for at least two reasons: it is a key to almost any country's economic development (or lack of it), and the division into industry and agriculture is the most commonly available disaggregation of output series. Perhaps the most thoroughly studied example of agro-industrial growth linkages is the development of the Punjab region of India and Pakistan that has taken place since the introduction of "green revolution" technology there in the 1960s. Drawing on the empirical work of Child and Kaneda (1975) and Chadha (1986), Stewart and Ghani (1991) state that in the Indian Punjab

In the early stages, much of the industrial growth was due to pecuniary externalities--i.e., improved markets for industrial products arising from linkages with agriculture....The strong linkages present can be seen in the geographical spread of industries which closely corresponds to the agricultural development of the state (p. 583).

Stewart and Ghani also note the presence of "informational externalities" within the agricultural and industrial sectors. In agriculture

${ }^{3}$ Note that the balanced growth steady state is actually the end product of an out of steady state adjustment process that Hirschman (1958) would call "unbalanced growth". I reserve the term "unbalanced growth" for the situation, discussed below, where growth in one sector or region reduces rather than stimulates growth in the other sector or region. 
The new technology requires a specific combination of inputs which depend on soil conditions. An individual farmer wanting to adopt the new technology would have to incur the cost of acquiring information on input requirements. The farmer is not in a position fully to appropriate the benefits, however, since neighboring farmers, with similar soil conditions, may observe the input mix (p. 582).

In industry

Technologies were rapidly diffused by copying, sometimes aided by the transfer of labor from one firm to another (p. 585).

These within-sector knowledge spillovers will be incorporated into the growth mechanism I develop in section 1 below.

Less direct evidence for the interaction between agricultural and industrial growth that I describe is abundantly available. A strong association between agricultural growth and the growth of manufacturing establishments by region was found for the Philippines by Anderson and Khambata (1981). Tang (1958) and Nicholls (1969) present evidence that nearby industrial-urban development induced technological change in agriculture in the Southern Piedmont region of the United States and in Brazil, respectively. Using cross-national data, Nishimizu and Page (1988) and a strong partial correlation between total factor productivity growth in industry and agricultural growth during the period 1960-1980. Finally, evidence suggesting that the terms of trade mechanism described above is at work in India is contained in Ahluwalia and Rangarajan (1988, pp. 234-236), who find that the terms of trade for agriculture positively infuence agricultural investment and negatively influence industrial investment.

Now suppose that the output of sector $N$ is traded, so that the intersectoral terms of trade are determined on international markets rather than by the need to equate domestic supply and demand. Without the terms of trade adjustment mechanism, more rapid growth in one sector will merely serve to raise wages and lower profitability in the other sector, inducing a cumulative decline in the slower-growing sector. I call this situation "unbalanced growth". We see that the presence of a labor market that is integrated across sectors or regions is crucial to the existence of unbalanced growth, as opposed to growth along different steady state paths as might occur among different countries. Good 
historical examples are the deindustrializations that occurred in Burma, Philippines, and Thailand with the increase in specialization in rice production for export during the period 1870-1938, as documented by Resnick (1970). Unbalanced growth would also seem to be a good description of the decades-long declines of the Northeast region of Brazil relative to the South and the South of Italy relative to the North. The population share of the Brazilian Northeast declined monotonically from 46.7 percent in 1872 to 29 percent in 1980, with net emigration being reported in every ten- or twenty-year period for which data is available (Baer 1989, pp. 317, 326). The Italian case will be discussed in some detail in section 4 below. Determination of the aggregate growth rate of an economy along an unbalanced growth path is discussed in section 3 .

In the theoretical literature several papers stand out most clearly as antecedents for the present work. In Ranis and Fei (1961), adjustment in the intersectoral terms of trade leads to balanced growth in the same manner as in this paper. In their classical model endogenous growth is possible because labor is in unlimited supply, allowing capital to be accumulated without encountering diminishing returns. They do not, however, consider the case of fixed terms of trade and unbalanced growth. The two-country model of Grossman and Helpman (1990) has some important formal similarities to the unbalanced growth model in this paper. Their assumption that knowledge that accumulates in one country does not spill over to the other country parallels my assumption that knowledge acquired in one sector does not benefit the other sector. There are three steady states in their model, two where only the country that had a "head start" acquires knowledge while the other specializes in "traditional" production, and one unstable one where both countries acquire knowledge. Similarly, there are three steady states in my unbalanced growth model: two where the country specializes in the sector that had a "head start", and one

1n Thailand deindustrialization progressed least in the most geographically remote areas, as we would expect from the above discussion. In the Philippines substantial new industry arose through "forward linkages" to agro-processing, and something similar appears to have happened in the Chilean case disccussed in section 3 below (see especially Figure 9). 
unstable balanced growth steady state. However, Grossman and Helpman are not concerned with explaining the same phenomena as is this paper. They have no model comparable to my balanced growth model, and their two countries do not share a common labor market as do my two sectors. Murphy, Shleifer, and Vishny (1989) develop a model where an agricultural "leading sector" stimulates nontraded industrial production, but their analysis is comparative static and their chief concern is with the interaction of income distribution and the size of the domestic market for industry. Finally, Matsuyama (1991) allows agricultural productivity to either stimulate or retard industrial growth, depending on whether the economy is closed or open to international trade. Knowledge is accumulated in industry through learning-by-doing rather than by the decisions of profit-seeking firms, however, and there is no endogenous accumulation of knowledge in agriculture, ruling out balanced growth as defined above.

The plan for the remainder of this paper is as follows. In the first section I formally develop the mechanism of exponential growth on which all of the following analysis is based. Readers less interested in derivations can skim this rather long section. The next section completes the core model by embedding this mechanism in a two sector framework, and derives some results on steady state growth rates. The stability of the balanced growth path is also discussed. Section 3 analyzes what happens when an economy moves from balanced to unbalanced growth as a result of trade liberalization, and argues that the unbalanced growth model is useful for understanding the post-1973 economic performance of Chile. Section 4 uses the unbalanced growth model to analyze the effects of economic integration of separate regions or countries into one country. In the concluding section I summarize the results of the paper and explore the possibilities for extensions of the models presented.

1. The mechanism of growth

As stated in the introduction above, this paper intends to explore phenomena 
generated by the interaction of growth in different sectors of the economy. Its purpose is not to postulate a new mechanism for "endogenous growth". In section 1.1, therefore, I take what I believe is the most appropriate "off-the-shelf" mechanism as far as it can go in explaining the phenomena of interest. Unfortunately this turns out to be not far enough, and a "new" mechanism must be developed in the following subsection that adds both descriptive realism and explanatory power but loses some transparency. Indeed, it is this loss that makes explicit presentation of the results obtained using the off-the-shelf mechanism worthwhile.

\subsection{A candidate mechanism}

The candidate mechanism of growth is a discrete time version of what Romer (1989) in his survey of the endogenous growth literature calls the Krugman-Lucas model. This model has two special features that make it attractive for present purposes: the knowledge accumulated by each sector is specific to it, allowing the sectors potentially to grow at different rates, and the supply of knowledge to each sector is inexhaustible, suiting our assumption of relative backwardness. Specifically, knowledge accumulation in each sector takes place entirely through learning by doing according to the equation

$$
K_{i+1}^{j}=K_{i}^{j}+K \dot{j} \mu^{j} \dot{q}
$$

where $K_{\mathfrak{l}}^{j}$ is human capital (knowledge) specialized to the production of good $j$ at time $t, \mu^{j}$ is a constant "learning coefficient" for sector $j$, and $q$ is the fraction of the labor force devoted to producing output of sector $j$ at time t. ${ }^{3}$ Specialized knowledge in turn feeds into Ricardian production functions for each sector:

$$
Q \mathfrak{i}=K \mathfrak{i} \dot{i} \overline{\mathrm{L}},
$$

where $Q \hat{t}$ is output of sector $j$ at time $t$ and $\bar{L}$ is the inelastically supplied labor endowment of the economy. It is immediately clear that, given a steady state value of $\dot{b}$, a steady

Implicitly equation (1.1.1) assumes costless diffusion of knowledge among perfectly competitive frms within a sector so that no individual firm has an incentive to increase its employment in order to capture more technological progress. 
state growth rate $\mu^{\mathrm{j}} \ell^{\mathrm{j}}$ of sector $\mathrm{j}$ output per worker is determined.

Lucas (1988) supposes, as does the present paper, that there exist two sectors, the outputs of which are imperfect substitutes in consumption. He specifies the preferences of the representative consumer by the function

$$
\mathrm{U}\left(\mathrm{c}^{1}, \mathrm{c}^{2}\right)=\left[(1-\theta)\left(\mathrm{c}^{1}\right)^{p}+\theta\left(\mathrm{c}^{2}\right)^{p}\right]^{1 / p}, \rho<1,
$$

where $c^{j}$ is individual consumption of the output of sector $j$ and time subscripts have been omitted since the consumer has no intertemporal decisions to make. This utility function yields a constant elasticity in consumption equal to $\epsilon=1 /(1-\rho) \geq 0$. Given a wage w we can find aggregate demand functions

$$
\begin{aligned}
& C^{1}=\left\{\left(p^{1}\right)^{-\epsilon}(1-\theta)^{\epsilon} /\left[\left(p^{1}\right)^{1-\epsilon}(1-\theta)^{\epsilon}+\left(p^{2}\right)^{1-\epsilon}(\theta)^{\epsilon}\right]\right\} w \bar{L}, \\
& C^{2}=\left\{\left(p^{2}\right)^{-\epsilon}(\theta)^{\epsilon} /\left[\left(p^{1}\right)^{1-\epsilon}(1-\theta)^{\epsilon}+\left(p^{2}\right)^{1-\epsilon}(\theta)^{\epsilon}\right]\right\} w \bar{L},
\end{aligned}
$$

where $C^{j}$ is aggregate consumption and $p^{j}$ is the price of output of sector $j$.

Consider an autarkic economy (one where the output of both sectors is nontraded). In such an economy $C^{j}=Q^{j}$, and if we add the assumption of pure competition we also have $\mathrm{p}^{j}=w / K^{j}$. Clearly relative prices move inversely to physical productivity. We can then ask, if the physical productivity of one sector is initially growing faster, will the induced change in relative prices be sufficient to "pull along" the lagging sector? We can find the answer as follows. Noting that the derived demands for labor are given by dividing equations (1.1.4) by $\mathrm{K}^{1}$ and $\mathrm{K}^{2}$, respectively, the ratio of labor shares is given by

$$
\begin{gathered}
\epsilon_{\mathrm{t}}^{1} / \mathcal{L}_{\mathrm{t}}^{2} \\
=\left(\mathrm{p}_{\mathrm{t}}^{1}\right)^{-\epsilon}(1-\theta)^{\epsilon} \mathrm{K}_{\mathrm{t}}^{2} /\left(\mathrm{p}_{\mathrm{t}}^{2}\right)^{-\epsilon}(\theta)^{\epsilon} \mathrm{K}_{\mathrm{t}}^{1}=\left(\mathrm{p}_{\mathrm{t}}^{1} / \mathrm{p}_{\mathrm{t}}^{2}\right)^{-\epsilon}[(1-\theta) / \theta]^{\epsilon}\left(\mathrm{K}_{\mathrm{t}}^{2} / \mathrm{K}_{\mathrm{t}}^{1}\right) \\
=[(1-\theta) / \theta]^{\epsilon}\left(\mathrm{p}_{\mathrm{t}}^{1} / \mathrm{p}_{\mathrm{t}}^{2}\right)^{1-\epsilon} .
\end{gathered}
$$

If $\epsilon<1$, the rising relative price of the lagging sector causes its share of the labor force to increase, increasing its rate of physical productivity growth relative to the other sector. If $\epsilon>1$, the opposite happens. It seems reasonable to assume that the elasticity of substitution in consumption between agricultural and manufacturing output is low, in which case this model can explain the kind of sectoral growth interaction described in the 
introduction to this paper.

We can substitute equation (1.1.1) and $\mathrm{p}^{\mathrm{j}}=\mathrm{w} / \mathrm{K}^{\mathrm{j}}$ into equation (1.1.5) and rearrange slightly to get

$$
\left[\left(K_{\mathfrak{t}+1}^{1}-K_{\mathfrak{t}}^{1}\right) / K^{1}\right] /\left[\left(K_{\mathfrak{t}+1}^{2}-K_{\mathfrak{t}}^{2}\right) / K_{\mathfrak{t}}^{2}\right]=\left(\mu^{1} / \mu^{2}\right)[(1-0) / \theta]^{\epsilon}\left(K_{\mathfrak{t}}^{1} / K_{\mathfrak{t}}^{2}\right)^{\epsilon-1} .
$$

We see that there is a unique steady state knowledge stock ratio $K^{1} / K^{2}$ given by $\left\{\left(\mu^{1} / \mu^{2}\right)\{(1-\theta) / \theta]^{\epsilon}\right\}^{1 /(1-\epsilon)}$ (which is also the autarky price ratio $\left.\mathrm{p}^{2} / \mathrm{p}^{1}\right)$ and that for $\epsilon<1$ the steady state is globally stable. We also have $\mu^{1} \ell^{1}=\mu^{2} \ell^{2}$ in the steady state, which can be used in combination with the the full employment condition $\ell^{1}+\ell^{2}=1$ to obtain $\ell^{1}=$ $\mu^{2} /\left(\mu^{1}+\mu^{2}\right)$. The steady state autarky growth rate of GDP per worker is then

$$
g^{A}=\mu^{1} l^{1}=\mu^{1} \mu^{2} /\left(\mu^{1}+\mu^{2}\right) \text {. }
$$

Now suppose that the reason the output of our autarkic economy is nontraded is government barriers to international trade. If these barriers are removed our country faces a price ratio determined in world markets that I assume it is too small to influence. This opening causes the country to immediately specialize completely in one of the two sectors (unless the world price ratio is the same as our country's autarky price ratio), yielding a new steady state growth rate of GDP per worker equal to either $\mu^{1}$ or $\mu^{2}$ that is necessarily higher than $\mathbf{g}^{\mathrm{A}}$. This result is consistent with the cross-sectional empirical evidence relating openness to per capita GDP growth in LDCs (see Edwards 1992 for a survey).

What are the defects of this candidate mechanism for our purposes? First, we would like to be able to identify one sector as the "engine of growth". But in the above model, the sectors are symmetric in determining the steady state growth rate. Second, we would like insight into the sustained sectoral booms and declines that can follow the opening of national economies to international trade and into the growth of aggregate GDP during these long transitions. In the above model, however, there are no transition dynamics for the move from a closed to an open economy. Third, we would like to model the engine of growth and transition dynamics while retaining the responsiveness of the steady state growth rate to savings parameters or policies such as capital income taxation 
that is the hallmark of endogenous growth models. This is not possible if we use the candidate mechanism of growth.

\subsection{Addition of a more realistic process of knowledge acquisition}

In their study of the process of technological change, Pack and Westphal (1986) do not find that a backward country's firms acquire new knowledge as a costless by-product of production (the pure learning-by-doing model). Rather, they find that since this knowledge is foreign the country's firms must incur some direct cost to assimilate and adapt it. Because firms would be willing to incur this cost only if they expect to thereby increase future profits, incorporation of these findings into a mechanism of growth sets up the Schumpeterian tradeoff of allocative efficiency versus entrepreneurial rents that characterizes many endogenous growth models, for example those of Grossman and Helpman (1991).

Given the complexity relative to the candidate mechanism of growth that is added by this more realistic process of knowledge acquisition, it will be easiest to understand the mechanism of growth in my model if we begin by limiting our attention to the case where there is only one active sector. Output of this numeraire good is not storable and is traded freely on international markets. Production is carried out by identical price-taking firms, each managed by an identical entrepreneur. In any period the states of the entrepreneur's knowledge $K$ and the average level of knowledge in the industry $\bar{K}$ are given. The entrepreneur is also assumed to supply her entire time endowment E inelastically to production in every period. Technology displays constant returns to scale in entrepreneurial time, laborer time $L$, and intermediate goods $M$ (assumed to be imported at a price determined in world markets):

$$
Q=Q[H(\bar{K}, K) F(E, L), M]
$$

where the scalar $Q$ denotes output and the functions $Q, H$, and $F$ are all standard $C R S$ neoclassical production functions. The $\mathrm{H}$ function reflects the benefits of knowledge spillovers within an industry. As in Romer (1987), H is assumed to be linear homogeneous 
in order to allow the model to generate a constant (steady-state) growth rate. Time subscripts are omitted for now. In any period the entrepreneur wishes to maximize her profits (rents to her time), which are given by $Q-w L-p M$, where $w$ is the wage paid to hire labor and $p$ is the price of the intermediate good. This maximization yields the profit function $\Pi(H, w, p)$, where the constant argument $E$ has been suppressed to save notation. Entrepreneurs are assumed to be endowed with special talents not present in (or obtainable by) the labor force so their profits cannot be bid down by entry of new entrepreneur-firms. (On the other hand, it is reasonable to think that if $\Pi$ falls below w there will be exit.) In any period, the wage is determined by the need to clear the labor market:

$$
-\eta \Pi_{\mathbf{w}}=\overline{\mathrm{L}},
$$

where $\overline{\mathrm{L}}$ is the inelastically supplied labor endowment of the economy, $\Pi_{w}$ denotes the derivative of $\Pi$ with respect to the wage rate, and $\eta$ is the number of entrepreneurs. For simplicity I assume that population is stationary in the discussion below so that $\overline{\mathrm{L}}$ and $\eta$ are constants.

Now I introduce time into the model, which is measured in discrete periods. I assume that all agents have access to a perfect capital market for consumption and investment loans and that each agent is too small to affect the interest rate. The Fisher separation theorem then tells us we can consider the entrepreneur's intertemporal consumption and investment decisions separately. I suppose that entrepreneurs and workers all have the same constant intertemporal elasticity of substitution utility functions:

-The H function used in Romer (1987) is Cobb-Douglas with exponents that sum to one. He defines $\bar{K}$ as total knowledge rather than knowledge per entrepreneur. The latter formulation is more convenient here since with all entrepreneurs identical we will have $\mathrm{K}=\overline{\mathrm{K}}$. In this paper the only substantive effect of assuming that spillovers are a function of average rather than total knowledge is that a pure increase in scale of the economy (e.g., doubling the number of entrepreneurs and workers) has no effect on its equilibrium through the channel of spillovers. 


$$
\sum_{t_{0} \leq t<\omega} \delta^{t} c_{t}^{1-\sigma} /(1-\sigma), \sigma>0,0<\delta<1,
$$

where $c$ is an agent's consumption of the numeraire good, $\delta$ gives the rate of time discounting, and $1 / \sigma$ gives the intertemporal elasticity of substitution. Maximization of this utility function over sequences $\left\{c_{t}\right\}$ subject to the agent's intertemporal budget constraint yields the standard first-order condition

$$
\left(c_{t+1} / c_{t}\right)^{\sigma}=\delta\left(1+r_{t+1}\right)
$$

where $r$ is the interest rate. Clearly we can aggregate this first-order condition over all agents without regard to distribution of wealth, so we can write

$$
\left(C_{t+1} / C_{t}\right)^{\sigma}=\delta\left(1+r_{t+1}\right)
$$

where $\mathrm{C}$ is aggregate consumption. The interest rate is determined by the need to equate desired domestic savings with desired domestic investment, i.e., our country does not engage in international borrowing or lending.

The entrepreneur's optimal investment policy is to maximize the value of her wealth, i.e., to maximize the present value of her firm. This value is given by the discounted sum of the firm's net cash flows. I assume that the entrepreneur can treat the amount of knowledge she purchases from abroad as a continuous variable. The cost of acquiring knowledge from abroad includes a licensing fee proportional to the amount of knowledge purchased plus convex training costs analogous to the convex adjustment costs assumed in the standard neoclassical model of investment. This formulation is an attempt to incorporate the findings of Pack and Westphal (1986) that the effort of firms to assimilate and adapt foreign technology "takes the form of investments in technological capability, which is the ability to make effective use of technological knowledge" (p. 105), and that "For standard products, purchasing a license and technical help from the owner of proprietary knowledge is likely to be the least cost short-run decision" (p. 121). I specify the entrepreneur's net cash flow in period $t$ as

$$
N C F_{t}=\Pi\left(H_{t}, w_{t}, p\right)-\gamma I_{t}-\left(\beta / \bar{K}_{t}\right)\left(I_{t}\right)^{2}
$$


where $\gamma$ can be thought of as a licensing fee paid for knowledge acquired, $\beta / \bar{K}$ can be thought of as training costs per unit of time, and $I_{t}=K_{t+1}-K_{t} \geq 0$ is investment in knowledge. Following Teece (1976), ${ }^{7}$ I justify my specification of training costs as decreasing in $\bar{K}$ by learning by doing on the part of trainers: the cost of training entrepreneurs from a particular country declines with past experience in training as measured by the number of entrepreneurs from that country trained times the total amount of knowledge transferred. ${ }^{8}$ For simplicity it is assumed that variables determined abroad and thus exogenously to the economy I am studying do not vary with time. The value of the entrepreneur's frm is then given by

$$
\sum_{t_{0} \leq t<\infty}\left[\prod_{t_{0} \leq 8 \leq t}\left(1+r_{s}\right)^{-1} N C F_{t}\right] .
$$

The entrepreneur wants to maximize the value of her firm (1.2.5) with respect to the sequence $\left\{I_{l}\right\}$ subject to the equation of motion $K_{t+1}=K_{l}+I_{l}$. To solve this problem we form the Hamiltonian

$$
\mathscr{F}_{q}=\prod_{t_{0} \leq \leq \leq t}\left(1+\mathrm{r}_{\mathrm{s}}\right)^{-1}\left[\mathrm{NCF}_{\mathrm{t}}+\left(1+\mathrm{r}_{\mathrm{t}+1}\right)^{-1} \lambda_{\mathrm{l}+1}\left(\mathrm{~K}_{\mathrm{t}}+\mathrm{I}_{\mathrm{t}}\right)\right]
$$

where $\left(1+r_{t+1}\right)^{-1} \lambda_{t+1}$ is the shadow price of knowledge accumulation. It is possible that $\mathscr{F}$ is not concave in the state variable $\mathrm{K}_{\mathfrak{t}}$, in which case the first-order conditions for a maximum may not be sufficient. In order to avoid this problem I assume that the profit function is concave in $K_{b}$, which is equivalent to assuming that the production function $Q$ does not display increasing returns to scale in the variable inputs under the entrepreneur's control.9 To gain further insight into what restrictions this places on the underlying

1On p. 47 Teece states that the costs of technology transfer are reduced by "Experience with tastes, skills, attitudes and knowledge of the infrastructure of the host country". He provides statistical evidence that transfer costs decrease with the number of transfers.

${ }^{8}$ We can nevertheless put the average level of knowledge $\bar{K}$ in the denominator of the training cost term by simply incorporating the number of entrepreneurs into the denominator of $\beta$. We should keep in mind, however, that now the scale of the economy affects its equilibrium through the channel of the training cost parameter.

In the presence of convex adjustment costs, the first-order conditions are sufficient for a 
technologies we recall that $\Pi_{\mathfrak{t}}=\Pi\left[\mathrm{H}\left(\overline{\mathrm{K}}_{\mathfrak{t}}, \mathrm{K}_{\mathfrak{t}}\right), \mathrm{w}_{\mathfrak{t}}, \mathrm{p}\right]$. We can write $\mathrm{H}\left(\overline{\mathrm{K}}_{\mathfrak{t}}, \mathrm{K}_{\mathfrak{t}}\right)=$ $\bar{K}_{\mathfrak{t}} \mathrm{H}\left(1, \mathrm{~K}_{\mathrm{t}} / \overline{\mathrm{K}}_{\mathrm{t}}\right)=\overline{\mathrm{K}}_{\mathrm{t}} \mathrm{h}\left(\mathrm{K}_{\mathrm{t}} / \overline{\mathrm{K}}_{\mathrm{t}}\right)$, where $\mathrm{H}\left(1, \mathrm{~K}_{\mathrm{t}} / \overline{\mathrm{K}}_{\mathrm{t}}\right) \equiv \mathrm{h}\left(\mathrm{K}_{\mathrm{t}} / \overline{\mathrm{K}}_{\mathrm{t}}\right)$. In order for the profit function to be concave in $K_{t}$ we therefore require that the convexity of $\Pi$ in its first argument be more than offset by the concavity of $h$. Assuming this to be true, the following first-order conditions are sufficient for a maximum to the entrepreneur's problem:

$$
\begin{gathered}
-\gamma-2\left(\beta / \bar{K}_{\mathfrak{t}}\right) I_{t}+\left(1+\mathrm{r}_{\mathrm{t}+1}\right)^{-1} \lambda_{\mathrm{t}+1} \leq 0, \text { with equality if } \mathrm{I}_{\mathrm{t}}>0 \\
\left(1+\mathrm{r}_{\mathrm{t}+1}\right)^{-1} \lambda_{\mathrm{t}+1}+\Pi_{\mathrm{K}_{\mathrm{t}}} h_{\mathrm{t}}=\lambda_{\mathrm{t}} \\
\lim _{\mathrm{t} \rightarrow \infty} \prod_{\mathrm{t}_{0} \leq \mathrm{s} \leq \mathrm{t}}\left(1+\mathrm{r}_{\mathrm{s}}\right)^{-1} \lambda_{\mathrm{t}} \mathrm{K}_{\mathrm{t}}=0,
\end{gathered}
$$

where $\Pi_{\mathrm{K}}$ is the derivative of $\Pi$ with respect to its first argument and $h$ is the derivative of h. If the solution is interior, the first two first-order conditions imply

$$
\mathrm{\Pi}_{\mathrm{K} t+1} h_{\mathrm{t}+1}=\left(1+\mathrm{r}_{\mathrm{t}+1}\right)\left[\gamma+2\left(\beta / \overline{\mathrm{K}}_{\mathrm{t}}\right) \mathrm{I}_{\mathrm{l}}\right]-\left[\gamma+2\left(\beta / \overline{\mathrm{K}}_{\mathrm{t}+1}\right) \mathrm{I}_{\mathrm{t}+1}\right] .
$$

For simplicity I assume that every entrepreneur begins with the same initial stock of knowledge $K_{0}$, so that they all choose identical investment sequences $\left\{I_{t}\right\} .10$ In this case $\mathrm{K}_{\mathfrak{t}} / \overline{\mathrm{K}}_{\mathrm{t}}$ always equals one and we can drop the time subscript from $h$.

I now demonstrate that this economy is capable of growing at a constant, positive rate indefinitely, i. e., that a positive steady state growth rate can exist. Let us suppose that knowledge is growing at the rate $g$, so that $\overline{\mathrm{K}}_{t+1}=\overline{\mathrm{K}}_{\mathrm{t}}(1+\mathrm{g})$ for all $\mathrm{t}$. It can be shown that the production function (1.2.1) implies that $\Pi$ is homogeneous of degree one in $H$ and $w$. It follows that $\Pi_{K}$ and $\Pi_{\nabla}$ are homogeneous of degree zero in $\bar{K}$ and $w$, treating $h$ as a constant. From the labor market clearing condition (1.2.2) we then have the result that

\footnotetext{
maximum even if there are constant returns to scale in the variable inputs under the entrepreneur's control, leading to a profit function that is linear in $\mathrm{K}$.

${ }^{10}$ Even if entrepreneurs begin with different initial stocks of knowledge, I conjecture that the concavity of each firm's profit function in its own knowledge will cause all firms to converge after some time to the same $K$, after which time investment sequences will be identical. Indeed, in the absence of adjustment costs and nonnegativity constraints on investment it can be shown that this convergence will occur in just one period.
} 
the wage rate must grow at the same rate as $\bar{K}$. Therefore $w / \bar{K} \equiv x$ is constant along this hypothetical steady state growth path. Turning to the entrepreneur's first-order condition (1.2.6), we see that in a steady state we can rewrite the left-hand side as $\Pi_{K}(h, x, p, E) h$, while the right-hand side equals $r(\gamma+2 \beta g)$. Since all arguments of $\Pi_{K}$ are constant along a steady state growth path, if consumption is also growing at a constant rate than $r$ is constant from (1.2.3) and a steady state growth equilibrium is possible. To check this, note first that the lack of international financial nows requires balanced trade in every period $t$ :

$$
\eta \mathrm{Q}-\mathrm{C}=\eta \gamma \mathrm{I}+\eta(\beta / \overline{\mathrm{K}})(\mathrm{I})^{2}-\mathrm{p} \eta \Pi_{\mathrm{p}}
$$

where $\Pi_{p}$ denotes the derivative of the profit function with respect to the price of the intermediate good. The left-hand side of this expression gives the value of exports of the numeraire good and the right-hand side gives the value of imports from abroad. Using the fact that production is constant returns to scale in $E, L$, and $M$, we substitute $Q=\Pi-w \Pi_{w}-p \Pi_{p}$ into the last expression and rearrange to get

$$
\mathrm{C}=\eta\left[\Pi-\gamma \mathrm{I}-(\beta / \overline{\mathrm{K}})(\mathrm{I})^{2}-w \Pi_{w}\right]
$$

which simply states that in equilibrium expenditure on the consumption good exhausts net cash now of entrepreneurs and wages of workers. We can rewrite (1.2.7) as

$$
\mathrm{C}=\overline{\mathrm{K}} \eta\left[\Pi(\mathrm{h}, \mathrm{x}, \mathrm{p}, \mathrm{E})-\gamma \mathrm{g}-\beta(\mathrm{g})^{2}-\mathrm{x} \Pi_{\mathrm{w}}\right],
$$

so it is clear that consumption also grows at the same rate as $\overline{\mathrm{K}}$ along our hypothetical steady state path.

I now show that any steady state growth rate $g$ is unique, and that $g>0$ for some parameter values. First note that in the steady state we can write (1.2.3) as

$$
g=[\delta(1+r)]^{1 / \sigma}-1
$$

This equation determines an upward-sloping curve in $r, g$ space. It is plotted for the case $\sigma=1$ in Figure 1. 


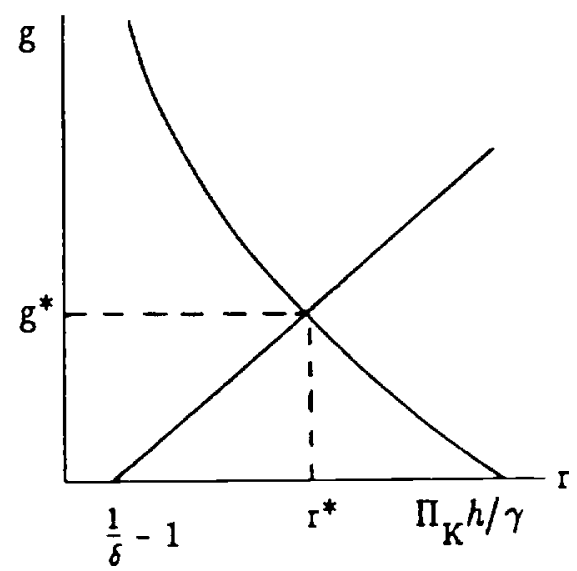

Figure 1: The steady state growth rate is uniquely determined

Second, we can rewrite the steady state entrepreneurial first order condition as

$$
\mathrm{g}=\left[\Pi_{\mathrm{K}}(\mathrm{h}, \mathrm{x}, \mathrm{p}, \mathrm{E}) \mathrm{h} / \mathrm{r}-\gamma\right] / 2 \beta
$$

Since, as we have already seen, $\mathrm{x}$ is uniquely determined by (1.2.2), it is clear that the curve determined by (1.2.10) is unambiguously downward-sloping in Figure 1. Moreover, we can shift this curve up (down) arbitrarily by decreasing (increasing) $\gamma$, holding all other parameters constant. Thus depending on the parameters of the economy either a unique, positive steady state growth rate exists or no steady state growth is possible. Note that in either case a unique interest rate 11 and wage per unit of knowledge are also determined, as is a unique level of consumption per unit of knowledge denoted by $z$ and determined by

$$
z=\eta\left[\Pi(h, x, p, E)-\gamma g-\beta(g)^{2}-x \Pi_{w}\right] .
$$

With the aid of Figure 1 we can demonstrate that the steady state growth rate in my model shows the same responses to changes in the efficiency of new knowledge acquisition as in the model of the previous subsection. It is clear from equation (1.1.7) that the steady state growth rate in the model of section 1.1 increases with either learning

1IIn order for a solution to the entrepreneur's maximization problem to exist, it must be the case that $\mathrm{g}^{*}<\mathrm{r}^{*}$, where the asterisk denotes the unique steady state value. From equation $(1.2 .9)$ this implies $\delta<\left(1+\mathrm{I}^{*}\right)^{\sigma-1}$, so the intertemporal elasticity of substitution cannot be too much greater than one. 
coefficient $\mu$. Similarly, we can prove:

PROPOSITION 1.2.1: A decrease in the licensing fee $\gamma$ or a decrease in the cost of training $\beta$ increases $g^{*}$. Proof. A lower $\gamma$ shifts up the downward-sloping curve in Figure 1 and a lower $\beta$ rotates this curve up about its intersection with the horizontal axis. My model also displays the now-standard response of the steady state growth rate to savings behavior:

PROPOSITION 1.2.1: A decrease in the rate of time discounting increases $\mathbf{g}^{*}$. Proof. A higher $\delta$ shifts up the upward-sloping curve in Figure 1.

I leave it to the reader to demonstrate that taxation of income from savings reduces the steady state growth rate, as in Rebelo (1991).

There are two new features of my growth mechanism. The first is the positive effect on the steady state growth rate of increasing the size of the labor force while holding the number of entrepreneurs constant:

PROPOSITION 1.2.3: An increase in the size of the labor force $\overline{\mathrm{L}}$ increases $\mathrm{g}^{*}$. Proof. An increase in $\overline{\mathrm{L}}$ decreases the wage rate per unit of knowledge $\mathrm{x}^{*}$ that solves (1.2.2) and thereby increases profitability, shifting up the downward-sloping curve in Figure 1. The second new feature is the effect of the commodity terms of trade on the steady state rate of growth:

PROPOSITION 1.2.4: An improvement in the terms of trade, relected in a fall in the price of the imported intermediate good $\mathrm{p}$, increases $\mathrm{g}^{*}$. Proof. A fall in $\mathrm{p}$ increases profitability and shifts up the downward-sloping curve in Figure 1.

Suppose that a large share of the price of the imported intermediate good $p$ is transportation cost. Proposition 1.2.4 then suggests the possibility of increasing steady state growth by substituting for these imports. This possibility sheds light on a conflict among development economists over the benefits of "backward linkages". These benefits were emphasized by writers such as Baldwin (1963), who were extrapolating from the growth experience of less developed countries during the late nineteenth and early 
twentieth centuries when transportation costs (especially for raw materials) were much higher than at present. Writing about Taiwan in the 1960s, on the other hand, Riedel (1976) states, "it might be argued that Taiwan has been so successful precisely because its industrial structure lacks backward linkages" (p. 320). Even in the high transportation cost case, however, one must be careful before concluding that import substitution will raise the steady state growth rate. Suppose that temporary protection were imposed in order to establish a domestic intermediate goods sector, and that in true Hirschmanian fashion the demand for import substitutes thus created called forth its own supply of entrepreneurs, leading to establishment of a balanced growth steady state at which all domestic demand for intermediate good output is met at a price lower than the import price inclusive of transportation costs. 12 This clearly "successful" case of import substitution does not necessarily raise the steady state growth rate. The reason is that the competing demand for labor thus established tends to raise the wage rate per unit of knowledge. In the case where $Q$ and $F$ are Cobb-Douglas, it is easy to construct numerical examples where establishment of backward linkages through successful import substitution raises $\mathrm{g}^{*}$ and numerical examples where the opposite occurs.

\section{Tradeables as the engine of growth}

I now introduce the second, "following" productive sector into my model. Its output is not traded internationally, for example due to high transportation costs or to government-imposed barriers to trade. For this reason the relative price or terms of trade between its output and the output of the traded goods sector is determined endogenously. Aside from the fact that its output is nontraded, the behavioral assumptions for the second sector are the same as for the first. Two additional important assumptions concerning intersectoral behavior mentioned in the introduction to this paper are necessary, however.

12For a full investigation of the properties of this steady state see Rauch (1992). 
First, the managerial talents of entrepreneurs are entirely sector-specific so that no intersectoral mobility of entrepreneurs in response to differential rents is possible. Second, stocks of knowledge are also entirely sector-specific, so that no spillovers of knowledge between sectors take place. These assumptions lead naturally to identification of the two sectors with agriculture and industry, but could also be suitable for application to two regions, where not only geographic distance but also cultural and even linguistic differences hamper intersectoral mobility of entrepreneurs and information.

\subsection{Steady state growth}

We saw in the previous section that reductions in the cost of knowledge acquisition (decreases in $\gamma$ or $\beta$ ) in the traded goods sector increased the steady-state growth rate of the economy. If in fact the traded goods sector "drives" regional growth, this should not be true for the nontraded goods sector. Instead, decreases in these parameters for nontradeables should have only level effects, reducing the cost of nontraded goods to consumers in the steady state.

Denote the traded and nontraded sectors by a superscript $\mathrm{T}$ and $\mathrm{N}$, respectively. In addition to the growth rate, interest rate, and wage per unit of (sector $\mathrm{T}$ ) knowledge, two new variables must now be determined in the steady state: the terms of trade between the nontraded and traded sectors $\mathrm{p}$ and the ratio of knowledge stocks $\overline{\mathrm{K}}^{\mathrm{T}} / \overline{\mathrm{K}}^{\mathrm{N}} \equiv \mathbf{k}$. The two additional equations are the optimal investment decision for sector $\mathrm{N}$ entrepreneurs and the market clearing equation for sector $\mathrm{N}$ output.

To keep matters simple I drop the intermediate good from my model. In the absence of these inputs, we write each sector's firm-level production function as

$$
Q^{j}=H^{j}\left(\bar{K}^{j}, K^{j}\right) F^{j}\left(E^{j}, L^{j}\right), j=T, N .
$$

It is then easily shown that we obtain the profit functions $\Pi^{\mathrm{T}}\left(\mathrm{H}^{\mathrm{T}}, w\right)$ and $\Pi^{\mathrm{N}}\left(\mathrm{pH}^{\mathrm{N}}, w\right)$, where the constant arguments $\mathrm{E}^{\mathrm{j}}$ have been suppressed to save notation. We see that the role played by the intersectoral terms of trade is similar to the role played by the international terms of trade in the one-sector model of section 1.2: there an increase in $p$ 
reduced profits in the traded goods sector, while here it increases profits in the nontraded goods sector that is competing with the traded goods sector for scarce resources.

Since there are only two variable arguments in each of the profit functions, to avoid confusion with the one-sector model I denote the derivatives with respect to each of these arguments by $\Pi_{1}^{j}$ and $\Pi \prod_{2}$, respectively. We can then write the labor market clearing condition as

or

$$
\begin{aligned}
& -\eta^{\mathrm{T}} \Pi_{2}^{\mathrm{T}}\left(\mathrm{B}^{\mathrm{T}}, \mathrm{w}\right)-\eta^{N} \Pi_{2}^{\mathrm{N}}\left(\mathrm{pH}^{\mathrm{N}}, \mathrm{w}\right)=\overline{\mathrm{L}} \\
& -\eta^{\mathrm{T}} \Pi_{2}^{\mathrm{T}}\left(\mathrm{h}^{\mathrm{T}}, \mathrm{x}\right)-\eta^{\mathrm{N}} \Pi_{2}^{\mathrm{N}}\left(\mathrm{ph}^{\mathrm{N}}, \mathrm{kx}\right)=\overline{\mathrm{L}},
\end{aligned}
$$

where $x$ is the wage per unit of sector $T$ knowledge.

Consumers can now choose to allocate their consumption expenditure to either $\mathrm{T}$ or $N$ output. We therefore change the consumer objective function in section 1.2 to

$$
\sum_{t_{0} \leq t<\infty} \delta^{t}\left[U\left(c_{t}^{T}, c_{t}^{N}\right)\right]^{1-\sigma} /(1-\sigma), \sigma>0,0<\delta<1,
$$

where $U\left(c_{t}^{T}, c_{t}^{N}\right)$ is linear homogeneous. This linear homogeneity implies that the marginal utilities $\partial U / \partial c_{t}^{T}$ and $\partial U / \partial c_{t}^{N}$ are functions only of the ratio $c_{t}^{N} / c_{t}^{T}$, which in turn implies from the first-order condition $\left(\partial U / \partial c_{t}^{N}\right) /\left(\partial U / \partial c_{t}^{T}\right)=p_{t}$ that $c_{t}^{N} / c_{t}^{T}$ is a function only of the price ratio $p_{t}$. We can therefore write $U\left(c_{t}^{T}, c_{t}^{N}\right)=c_{t}^{T} v\left(p_{t}\right)$, and the Euler equation for consumption of the traded good becomes

$$
\left(c_{t+d}^{T} / c_{t}^{T}\right)^{\sigma}=\left[v\left(p_{t}\right) / v\left(p_{t+1}\right)\right]^{\sigma}\left[\left(\partial U / \partial c_{t+1}^{T}\right) /\left(\partial U / \partial c_{t}^{T}\right)\right] \delta\left(1+r_{t+1}\right) .
$$

Again we can aggregate this first-order condition without regard to distribution of wealth, yielding a new version of equation (1.2.3):

$$
\left(C_{t+1}^{T} / C_{t}^{T}\right)^{\sigma}=\left[v\left(p_{t}\right) / v\left(p_{t+1}\right)\right]^{\sigma}\left[\left(\partial U / \partial c_{t+1}^{T}\right) /\left(\partial U / \partial c_{t}^{T}\right)\right] \delta\left(1+r_{t+1}\right) .
$$

We can find the optimal investment policy for an entrepreneur in each sector following the same procedure as in section 1.2. We obtain a new version of equation (1.2.6) for each sector:

$$
\begin{gathered}
\Pi_{1 t+1}^{\mathrm{T}} h_{t+1}^{\mathrm{T}}=\left(1+\mathrm{I}_{\mathrm{t}+1}\right)\left[\gamma^{\mathrm{T}}+2\left(\beta^{\mathrm{T}} / \overline{\mathrm{K}}_{\mathrm{t}}^{\mathrm{T}}\right) \mathrm{I}_{\mathrm{t}}^{\mathrm{T}}\right]-\left[\gamma^{\mathrm{T}}+2\left(\beta^{\mathrm{T}} / \overline{\mathrm{K}}_{\mathrm{t}+1}^{\mathrm{T}}\right) \mathrm{I}_{\mathrm{t}+\mathrm{l}}^{\mathrm{T}}\right] \\
\Pi_{\mathrm{t}+1}^{\mathrm{N}} h_{\mathrm{t}+1}^{\mathrm{N}} \mathrm{p}_{\mathrm{t}+1}=\left(1+\mathrm{r}_{\mathrm{t}+1}\right)\left[\gamma^{\mathrm{N}}+2\left(\beta^{\mathrm{N}} / \overline{\mathrm{K}}_{\mathrm{t}}^{\mathrm{N}}\right) \mathrm{I}_{\mathrm{t}}^{\mathrm{N}}\right]-\left[\gamma^{\mathrm{N}}+2\left(\beta^{\mathrm{N}} / \overline{\mathrm{K}}_{\mathrm{t}+1}^{\mathrm{N}}\right)_{\mathrm{t}+1}^{\mathrm{N}}\right] .
\end{gathered}
$$


Finally, we add the condition that the market for nontraded output must clear in every period. We note that $C^{N}=\eta^{N} \Pi_{1}^{N} H^{N}$ and $C^{T} / C^{N}=A(p), A^{\prime}>0$. Balanced trade yields $\mathrm{C}^{\mathrm{T}}=\eta^{\mathrm{T}}\left[\mathrm{Q}^{\mathrm{T}}-\gamma^{\mathrm{T}} \mathrm{I}^{\mathrm{T}}-\left(\beta^{\mathrm{T}} / \overline{\mathrm{K}}^{\mathrm{T}}\right)\left(\mathrm{I}^{\mathrm{T}}\right)^{2}\right]-\eta^{\mathrm{N}}\left[\gamma^{\mathrm{N}} \mathrm{I}^{\mathrm{N}}+\left(\beta^{\mathrm{N}} / \overline{\mathrm{K}}^{\mathrm{N}}\right)\left(\mathrm{I}^{\mathrm{N}}\right)^{\boldsymbol{\gamma}}\right]$. We can combine these three equations with the fact that $Q^{T}=\Pi^{T}-w \Pi_{2}^{T}=\Pi_{1}^{T} H^{T}$ to get the market clearing equation

$$
\eta^{\mathrm{T}}\left[\Pi_{1}^{\mathrm{T}} \mathrm{B}^{\mathrm{T}}-\gamma^{\mathrm{T}} \mathrm{I}^{\mathrm{T}}-\left(\beta^{\mathrm{T}} / \overline{\mathrm{K}}^{\mathrm{T}}\right)\left(\mathrm{I}^{\mathrm{T}}\right)^{\eta}\right]-\eta^{\mathrm{N}}\left[\gamma^{\mathrm{N}} \mathrm{I}^{\mathrm{N}}+\left(\beta^{\mathrm{N}} / \overline{\mathrm{K}}^{\mathrm{N}}\right)\left(\mathrm{I}^{\mathrm{N}}\right)^{2}\right]=\mathrm{A}(\mathrm{p}) \eta^{\mathrm{N}} \Pi_{1}^{\mathrm{N}} \mathrm{H}^{\mathrm{N}} \text {. }
$$

In the steady state $p$ is constant so (2.1.3) reduces to (1.2.9), giving us the same upward-sloping curve in Figure 1 as in the one-sector model. For the traded goods sector (2.1.4) reduces to the equivalent of (1.2.10):

$$
g=\left[\Pi_{1}\left(\mathbf{h}^{\mathrm{T}}, \mathbf{x}\right) h^{\mathrm{T}} / \mathrm{r}-\gamma^{\mathrm{T}}\right] / 2 \beta^{\mathrm{T}} .
$$

In the one-sector model $x$ was determined by the labor-market clearing equation (1.2.2) alone. The labor-market clearing equation (2.1.2), however, involves the new variables $p$ and $\mathbf{k}$. To solve for the steady state, therefore, we need the steady-state entrepreneurial first-order condition for sector $\mathrm{N}$, which we obtain from (2.1.4):

$$
\mathrm{g}=\left[\Pi_{1}\left(\mathrm{ph}^{\mathrm{N}}, \mathrm{kx}\right) \mathrm{ph}^{\mathrm{N}} / \mathrm{r}-\gamma^{\mathrm{N}}\right] / 2 \beta^{\mathrm{N}},
$$

where we have used the fact that along a balanced growth path we have $g=I^{T} / \bar{K}^{T}=$ $\mathrm{I}^{\mathrm{N}} / \overline{\mathrm{K}}^{\mathrm{N}}$. We also need the market clearing equation for sector $\mathrm{N}$ output, which when we divide both sides by $\overline{\mathrm{K}}^{\mathrm{N}}$ can be written:

$$
\eta^{\mathrm{T}} \mathrm{k}\left[\Pi_{1}^{\mathrm{T}}\left(\mathrm{h}^{\mathrm{T}}, \mathrm{x}\right) \mathrm{h}^{\mathrm{T}}-\gamma^{\mathrm{T}} \mathrm{g}-\beta^{\mathrm{T}} \mathrm{g}^{2}\right]-\eta^{\mathrm{N}}\left[\gamma^{\mathrm{N}} \mathrm{g}+\beta^{\mathrm{N}} \mathrm{g}^{2}\right]=A(\mathrm{p}) \eta^{\mathrm{N}} \Pi_{1}^{\mathrm{N}}\left(\mathrm{ph}^{\mathrm{N}}, \mathrm{kx}\right) \mathrm{h}^{\mathrm{N}} \text {. }
$$

Determination of the steady state is summarized in Table 1.

I would like to show that the latter four equations in Table 1 determine a downward-sloping curve in Figure 1, thus demonstrating uniqueness of the steady state growth rate $g^{*}$ in the same manner as in the one-sector model of the previous section. It proves simpler to analyze whether an increase in $g$ causes a decrease in $r$ rather than vice versa. In section $A 2$ of the Appendix it is shown that the direct effect of $g$ on $r$ through the optimal investment decisions is indeed negative, under the sufficient but far from necessary condition that $A(p)-A^{\prime}(p) p \geq 0$. (This condition is satisfied, for example, if 


\section{Table 1: Steady State Growth}

consumption Euler equation:

$$
g=[\varnothing(1+r)]^{1 / \sigma}-1 .
$$

optimal investment decision, traded goods:

$$
g=\left[\Pi_{1}^{\mathrm{T}}\left(\mathrm{h}^{\mathrm{T}}, \mathbf{x}\right) h^{\mathrm{T}} / \mathrm{r}-\gamma^{\mathrm{T}}\right] / 2 \beta^{\mathrm{T}} .
$$

optimal investment decision, nontraded goods:

$$
g=\left[\Pi_{1}^{N}\left(p h^{N}, k x\right) p h^{N} / r-\gamma^{N}\right] / 2 \beta^{N} .
$$

labor market clearing:

$$
-\eta^{\mathrm{T}} \Pi_{2}^{\mathrm{T}}\left(\mathrm{h}^{\mathrm{T}}, \mathrm{x}\right)-\eta^{\mathrm{N}} \Pi_{2}^{\mathrm{N}}\left(p h^{\mathrm{N}}, \mathrm{kx}\right)=\overline{\mathrm{L}} .
$$

nontraded goods market clearing:

$$
\eta^{\mathrm{T}} \mathrm{k}\left[\Pi_{1}^{\mathrm{T}}\left(\mathrm{h}^{\mathrm{T}}, \mathrm{x}\right) \mathrm{h}^{\mathrm{T}}-\gamma^{\mathrm{T}} \mathrm{g}-\beta^{\mathrm{T}} \mathrm{g}^{2}\right]-\eta^{\mathrm{N}}\left[\gamma^{\mathrm{N}} \mathrm{g}+\beta^{\mathrm{N}} \mathrm{g}^{2}\right]=\mathrm{A}(\mathrm{p}) \eta^{\mathrm{N}} \Pi_{1}^{\mathrm{N}}\left(\mathrm{ph} \mathrm{h}^{\mathrm{N}}, \mathrm{kx}\right) \mathrm{h}^{\mathrm{N}} .
$$

$\mathrm{U}\left(\mathrm{c}_{\mathrm{t}}^{\mathrm{T}}, \mathrm{c}_{\mathrm{t}}^{\mathrm{N}}\right)$ is a CES function with elasticity of substitution $\leq 1$.) However, there is an indirect effect of $\mathrm{g}$ on $\mathrm{r}$ through the nontraded goods market clearing condition that is positive under the same sufficient condition. Intuitively, the positive indirect effect results from the fact that a larger $g$ means less current consumption expenditure, causing a fall in sector $\mathrm{N}$ output that reduces labor demand and the wage per unit of sector $\mathrm{T}$ knowledge and thereby increases profitability. Under the assumption that the direct effect dominates the indirect effect, ${ }^{13}$ I prove the following Propositions in section A2 of the Appendix: PROPOSITION 2.1.1: An increase in the size of the labor force $\overline{\mathrm{L}}$ increases $\mathrm{g}^{*}$ under the sufficient condition that $A(p)-A^{\prime}(p) p \geq 0$.

${ }^{13}$ The downward slope in $r, g$ space of the curve determined by the latter four equations in Table 1 is a stronger condition than is needed to establish uniqueness of the steady state growth rate or to establish the Propositions below. However, maintaining this assumption allows the reader to see the parallels between the complete model and the model of section 1.2 and conserves on space by eliminating the need to give the specific weaker sufficient conditions as I state each Proposition. 
PROPOSITION 2.1.2: An increase in the cost of knowledge acquisition $\gamma^{\mathrm{T}}$ decreases $\mathrm{g}^{*}$ under the sufficient conditions that $A(p)-A^{\prime}(p) p \geq 0$ and $r \geq g h^{T} / h^{T}$. Since restrictions that imply $r>g$ have already been assumed (see footnote 11), the latter condition is satisfied if $h^{\mathrm{T}} \leq \mathrm{h}^{\mathrm{T}}$, which holds if, for example, the function $\mathrm{H}^{\mathrm{T}}$ is Cobb-Douglas. PROPOSITION 2.1.3: An increase in the cost of training $\beta^{T}$ decreases $g^{*}$ under the sufficient conditions that $A(p)-A^{\prime}(p) p \geq 0$ and $r \geq g h^{T} / 2 h^{T}$.

Propositions 2.1.2-2.1.3 correspond to Proposition 1.1 in section 1.2, and are consistent with the idea that the traded goods sector is the "engine of growth". The results are different when we turn to sector $\mathrm{N}$.

PROPOSITION 2.1.4: An increase in the cost of knowledge acquisition $\gamma^{\mathrm{N}}$ increases $\mathrm{g}^{*}$ if $U\left(c_{t}^{T}, c_{t}^{N}\right)$ is Cobb-Douglas. This effect approaches zero as $\beta^{N}$ approaches zero.

PROPOSITION 2.1.5: An increase in the cost of training $\beta^{N}$ decreases $g^{*}$ if $U\left(c_{t}^{T}, c_{t}^{N}\right)$ is Cobb-Douglas. This effect approaches zero as $\gamma^{\mathrm{N}}$ approaches zero.

Propositions 2.1.4-2.1.5 show that changes in the cost of licensing knowledge for the "lagging" sector perversely affect steady state growth, and changes in steady state growth caused by either sector $\mathrm{N}$ knowledge acquisition parameter can be made arbitrarily small by shrinking the size of the other parameter. We can see the underlying reason for this property of my model by looking at Table 1 and observing that the only way in which sector $N$ can influence $g^{*}$ is by changing $x^{*}$, the steady state wage per unit of sector $T$ knowledge.

Unlike their effects on steady state growth, the effects of the sector $\mathrm{N}$ knowledge acquisition parameters on $\mathrm{p}^{*}$ should be robust. Consider a decrease in $\gamma^{\mathrm{N}}$ or $\beta^{\mathrm{N}}$. This reduction in the cost of knowledge acquisition relative to sector $T$ requires a decrease in the profitability of knowledge acquisition relative to sector $\mathrm{T}$ in order to maintain balanced growth, and this decrease in relative profitability is most directly accomplished by moving the terms of trade against sector $N$. In order to do the comparative static exercises needed to verify this level effect intuition, I first need to establish that $\mathrm{p}^{*}$ is unique. Conditions 
have already been given under which the balanced growth rate $\mathrm{g}^{*}$ and interest rate $\mathrm{r}^{*}$ are unique. In section $A 2$ of the Appendix I prove that $p^{*}, k^{*}$, and $x^{*}$ are all uniquely determined given $g^{*}$ and $r^{*}$ under the sufficient condition $A(p)-A^{\prime}(p) p \geq 0$. It is then easy to also prove:

PROPOSITION 2.1.6: An increase in the cost of knowledge acquisition $\gamma^{N}$ (training $\beta^{N}$ ) increases $p^{*}$ if $U\left(c_{t}^{T}, c_{t}^{N}\right)$ is Cobb-Douglas and $\beta^{N}\left(\gamma^{N}\right)$ equals zero.

Under the same conditions given for Proposition 2.1.6 it is easy to show that $\mathbf{k}^{*}$ also increases with $\gamma^{N}$ or $\beta^{N}$.14 The intuition is that the increase in $\gamma^{N}$ or $\beta^{N}$ temporarily depresses knowledge growth in sector $N$, causing $k^{*}$ to rise until the increase in $\mathrm{p}^{*}$ restores balanced growth.

\subsection{Nontradeables: Pulled along or falling behind?}

Since the model of section 2.1 yields exponential growth, we must normalize on one of the knowledge stocks to obtain a stationary model whose stability we can analyze. In the normalized model there is only one state variable, the knowledge stock ratio $k$, but two control variables, the normalized investments of each sector. Unlike in the model of section 1.1, a mathematically formal determination of whether my model is globally stable given any set of parameters has not proved feasible. While it is in fact possible to obtain some analytical results concerning local stability for certain special cases, it proves more illuminating to combine an intuitive approach to the questions of interest with some supporting simulations suggested by the model of section 1.1 .

We saw in section 2.1 that, when $g^{*}$ and $r^{*}$ are uniquely determined, under weaker conditions so are the steady state knowledge stock ratio $\mathrm{k}^{*}$ and the steady state terms of trade $p^{*}$. Suppose that at some point in time $k>k^{*}$. If the balanced growth path is

14If these conditions were eliminated while retaining the conditions for uniqueness, the effect of an increase in $\gamma^{N}$ or $\beta^{N}$ on $\mathrm{p}^{*}$ would be determined by the ratio of two $5 \times 5$ determinants. The determinant in the denominator would be positive, while the determinant in the numerator would contain only one negative term, similar to the "indirect effect" above. This term would have to be dominated for the determinant to be positive. Details are available from the author on request. 
stable, sector $\mathrm{T}$ will "pull along" sector $\mathrm{N}$ by bidding up its terms of trade sufficiently above $p^{*}$ to cause it to acquire knowledge at a faster rate than does sector $T$. If the balanced growth path is unstable, this terms of trade effect is too weak and sector $N$ falls further and further behind sector $\mathrm{T}$ in rate of knowledge acquisition, losing the competition for labor and capital resources. The analogy to the model of section 1.1 is clear: there an initial knowledge stock ratio greater than its balanced growth steady state value also yields terms of trade for the lagging sector above their steady state value, which causes it to acquire knowledge at a faster rate than the leading sector if the elasticity of substitution in consumption is sufficiently small (less than unity).

This analogy suggests that the value of the elasticity of substitution in consumption will be the key determinant of whether the balanced growth path in my model is stable. I now try to see if this insight is borne out by simulations. In particular, I assign to $\mathrm{U}\left(\mathrm{c}^{\mathrm{T}}, \mathrm{c}^{\mathrm{N}}\right)$ the CES functional form used in equation (1.1.3) above and consider what happens to stability as I vary the elasticity of substitution $\epsilon$. Turning to the nontraded goods market clearing equation in Table 1 above, it is easily shown that the function $A(p)$ associated with this CES specification is $\{[(1-\theta) / 0] p\}^{\varepsilon}$. If $\theta=.5$ and the other parameters of the model are such that $\mathrm{p}^{*}=1$, then one can see from Table 1 that it is possible to vary $\epsilon$ without changing the balanced growth steady state. This is what I do in Figure 2, which shows the results of simulations that all start with a knowledge stock ratio ten percent above the balanced growth steady state value but have different values of $\epsilon$. As expected, the rate of convergence to the steady state declines with $\epsilon$. For $\epsilon>3.5$, the model becomes locally unstable. Different initial percentage deviations of the knowledge stock ratio or different underlying model parameters yield qualitatively similar results.

Analysis of why $\epsilon>>1$ was required to generate instability in my model proves helpful in understanding how the balanced growth process operates. In the model of section 1.1 the variable affecting relative rates of knowledge acquisition is labor force shares, while in my model it is relative profitability. Substituting $K_{\mathfrak{l}}^{2} / K_{\mathfrak{l}}^{1}$ for $p_{\mathfrak{l}}^{1} / p_{\mathfrak{l}}^{2}$ in the 
last line of equation (1.1.5), we see that labor force shares are unaffected by a change in the knowledge stock ratio if $\epsilon=1$, and move inversely (directly) with the knowledge stock ratio if $\epsilon<1(\epsilon>1)$, leading to stability (instability). In my model, however, one can make a heuristic argument that relative profitability will be unaffected by a change in the knowledge stock ratio only for some $\epsilon>1$. Suppose we disturb the steady state depicted in Table 1 by a unanticipated ten percent increase in $k$. Holding $g$ constant, this requires adjustments in $\mathrm{p}$ and $\mathrm{x}$ to clear the nontraded goods and labor markets. Ignoring the term $\eta^{N}\left[\gamma^{N} g+\beta^{N} g^{2}\right]$ in the nontraded goods market clearing equation, we can see that for $\epsilon=1$ a ten percent increase in $p$ and a constant $x$ will clear both markets. Profitability of investment in the traded goods sector is then unchanged, but we can see that profitability of investment in the nontraded goods sector increases. Unchanged relative profitability thus requires a percentage increase in $p$ less than that in $k$, implying $\epsilon>1$ in order to clear the nontraded goods market. Inclusion of the term $\eta^{N}\left[\gamma^{N} g+\beta^{N} g^{2}\right]$ only strengthens this argument. Thus we see from Figure 2 that, as $\epsilon$ increases from unity towards its "break-even" level, the percentage increase in $p$ drops from about equal to about half the percentage increase in $\mathbf{k}$.

Figure 3 gives an example of the balanced growth process at work. It is suggested by the experience of the Punjab cited in the introduction to this paper, where extension services brought Green Revolution technology to the agricultural sector, stimulating its growth which in turn stimulated industrial growth. An unanticipated fall in training costs $\beta^{T}$ causes the rate of investment in the traded goods sector to accelerate above its previous steady state level. The terms of trade for sector $\mathrm{N}$ are bid up, "pulling along" investment there and allowing its rate of growth to catch up to that of sector $T$, thereby establishing a new steady state at which growth in both sectors is permanently higher.

3. Liberalization and unbalanced growth, with an application to Chile

Suppose that sector $\mathrm{N}$ output is not traded internationally due to 
government-imposed barriers to trade. We saw in the model of section 1.1 that (generically) trade liberalization put the economy on a higher steady state growth path. I begin this section by showing that the same is true in my model, and then go on to simulate its transition dynamics (nonexistent in the model of section 1.1) and apply this simulation to the Chilean economy after 1973.

I suppose that after liberalization the intersectoral terms of trade are fixed at $\mathrm{p}^{* *}$ by world markets. In section Al of the Appendix I prove that if a positive balanced growth rate is feasible, then given any $\mathrm{p}^{* *}$ the balanced growth rate $\mathrm{g}^{* *}$, interest rate $\mathrm{r}^{* *}$, wage per unit of sector $T$ knowledge $x^{* *}$, and ratio of sector $T$ to sector $N$ knowledge $k^{* *}$ are all uniquely determined. In other words, for any $p$ there exists a unique solution to the first four equations in Table 1 (the market clearing equation for nontraded goods is no longer relevant), provided $\mathrm{g}^{* *}>0$. As discussed in the introduction to this paper, in the absence of the terms of trade adjustment mechanism this steady state should be globally unstable, by which I mean that given any initial $\mathbf{k} \neq \mathbf{k}^{* *}$ the economy will diverge still further from $\mathbf{k}^{* *}$. A heuristic argument for this instability runs as follows. Suppose that at some point in time $\mathbf{k}>\mathbf{k}^{* *}$. (The argument is symmetric if $\mathbf{k}<\mathbf{k}^{* *}$.) This "head start" for sector $\mathrm{T}$ implies that the wage per unit of knowledge in sector $T$ relative to sector $N$ is lower than in the steady state, making the profitability of investment in sector T relative to sector $\mathrm{N}$ higher than in the steady state. Since the rate of knowledge acquisition in the two sectors is equal in the steady state, knowledge growth in sector $\mathrm{T}$ is now relatively higher, causing $k$ to increase still further. An analytical proof that the balanced growth steady state is globally unstable when the intersectoral terms of trade are fixed is given in Rauch (1992) for the case $\beta^{\mathrm{T}}=\beta^{\mathrm{N}}=0$.

Suppose that our country is on the balanced growth path of the model of section 2.1, and then policy makers decide to remove the protection given sector $N$, causing the 
domestic terms of trade to fall from $\mathrm{p}^{*}$ to the exogenously given world level $\mathrm{p}^{* *}$. 15 The following Proposition is proven in section A1 of the Appendix:

PROPOSITION 3.1: The balanced growth steady state knowledge stock ratio $\mathbf{k}^{* *}$ varies directly with the exogenously given terms of trade $\mathrm{p}^{* *}$.

It follows from Proposition 3.1 that the knowledge stock ratio $\mathrm{k}^{*}$ for the country prior to liberalization will be above the $\mathbf{k}^{* *}$ associated with the post-liberalization terms of trade, so after liberalization the country finds itself in a situation where sector $\mathrm{T}$ has more knowledge relative to sector $\mathrm{N}$ than balanced growth would warrant. Following the argument of the preceding paragraph, the country now embarks on an unbalanced growth path where $\mathrm{k}$ increases without limit. Along this divergent path wages are rising since investment in sector $T$ is positive. Nevertheless since $k$ is increasing we can see from the labor-market clearing condition that $x$, the wage per unit of sector $\mathrm{T}$ knowledge, falls steadily, increasing the profitability of knowledge acquisition in sector $\mathrm{T}$ and the share of the labor force that it employs. Thus investment and production in the economy ultimately become completely specialized in sector $\mathrm{T}$.

I can now state

PROPOSITION 3.2: Liberalization raises the steady state growth rate. Proof. We saw in section 2.1 that sector $\mathrm{N}$ only influences the steady state growth rate through its effect on $x$, the wage rate per unit of sector $T$ knowledge. Since its demand for labor in the labor market clearing equation of Table 1 goes to zero in the new steady state, the value of $x$ in the new steady state is clearly less than $x^{*}$ and thus the new steady state growth rate is greater than $\mathrm{g}^{*}$.

The shift from the balanced growth steady state to a one sector steady state is in essence equivalent to an increase in $\overline{\mathrm{L}}$ in the model of section 1.2, and thus Proposition 3.2 actually

15If $\mathrm{p}^{*}$ were below $\mathrm{p}^{* *}$ the output of sector $\mathrm{N}$ would be exported, contradicting the assumption that its output is nontraded. In the knife-edge case $\mathrm{p}^{*}=\mathrm{p}^{* *}$ the country remains on the balanced growth path. 
follows from Proposition 1.2.3.

Although the new steady state will be the same, the unbalanced growth path following liberalization may be very different depending on the relative sizes of the two sectors along the balanced growth path. Suppose, for example, that sector $N$ was by far the larger sector, perhaps by virtue of a much greater weight in consumer demand. Since the two sectors were growing at the same proportionate rate, sector $N$ was accounting for the bulk of aggregate investment. When its entrepreneurs reduce or cease their knowledge acquisition, the stimulus provided to investment in sector $\mathrm{T}$ by lower expected wages per unit of sector T knowledge may not be sufficient (because of convex training costs) to prevent a fall in the overall growth rate of the economy. Eventually, however, because sector $\mathrm{N}$ is now shrinking relative to sector $\mathrm{T}$, the accelerated grow th of the latler must dominate overall per capita income grow th so that the unbalanced growth rate becomes higher than the balanced growth rate. In sum, depending on the parameters of the economy, "liberalization" may cause an immediate acceleration of growth, a brief growth "recession", or a prolonged growth "depression" before the ultimate higher growth rate is allained.

I shall argue below that it is useful to view the Chilean economy after 1973 as being on an unbalanced growth path following a liberalization, with agriculture and manufacturing playing the roles of sectors $\mathrm{T}$ and $\mathrm{N}$, respectively. I focus on Chile because it is currently viewed by many policy makers from Latin America to Eastern Europe as a model for economic restructuring. I stick to this case study rather than looking at liberalization experiences more broadly because the Chilean trade liberalization was atypically clear-cut. According to Edwards and Edwards (1987), "Between 1974 and 1979 Chile was transformed from a highly closed economy, where international transactions were severely repressed, into an open economy whose foreign trade corresponded quite closely to the neoclassical ideal [p. 109]."

Since Chileans speak of the period 1974-1984 as a "lost decade" of economic growth, 
it is interesting to explore whether liberalization is in fact capable of generating a prolonged growth slowdown in my model starting from a balanced growth path that at least superficially mimics the pre-liberalization Chilean economy. I thus choose simulation parameters that yield a steady state balanced growth rate $g^{*}$ of two percent (roughly the Chilean average for 1950-1973), a ratio of sector $T$ to sector $N$ output along the balanced growth path of one-quarter (roughly equal to the ratio of agricultural to manufacturing output in Chile in 1973), and a new steady state growth rate (in an economy specialized in sector $\mathrm{T}$ ) of 4 percent (close to the Chilean average for 1984-1991). To facilitate simulation I adopt Cobb-Douglas functional forms for $\mathrm{F}^{\mathbf{j}}$ and $\mathrm{H}^{\mathrm{j}}$ and a CES functional form with $\epsilon=.5$ for U. Parameters are chosen to make sector $T$ production more labor-intensive than sector $\mathrm{N}$ production in line with the realities of agricultural and manufacturing production in Chile, but otherwise no additional attempts at verisimilitude are made in choosing parameters. Two concessions are made to the solution powers of the simulation program. 1) Agents are not allowed to anticipate the liberalization decision. This permits us to treat the balanced growth knowledge stock ratio $\mathrm{k}^{*}$ as a given initial condition, which results from entrepreneurial decisions in the previous period that turned out to be incorrect ex post. 2) The relative price of sector $\mathrm{N}$ output falls sufficiently to make it optimal for sector $\mathrm{N}$ entrepreneurs to cease all knowledge acquisition immediately, so that their investment is set to zero. In the simulation reported in Figure $4, p^{* *}$ is 18 percent lower than the balanced growth steady state value $\mathrm{p}^{*}$.

Figure 4 shows that the growth rate of GDP initially falls to one percent from the balanced growth rate of two percent. Essentially, this result occurs because the fall in the wage rate and interest rate due to decreased sector $N$ labor and investment demand, respectively, cause the sector $\mathrm{T}$ growth rate to jump immediately almost to its new steady state level of four percent. Since the share of sector $T$ in GDP immediately jumps from 20 percent to over 23 percent as a result of the relative price change alone (i.e., not counting labor force reallocation), a one percent growth rate for total GDP follows. 15 years are 
required for the growth rate to return to its balanced growth level of two percent.

While Figure 4 would appear to depict a "painful" process of transition to a higher steady state growth rate, in fact welfare as measured by $\Sigma_{t=1}^{\top}(.95)^{t-1} \log \left(U_{t}\right)$ is higher at every $\tau$ with liberalization than without. The reason is that liberalization causes a fall in the price of sector $\mathrm{N}$ output, which by assumption is the good on which consumers spend most of their income. ${ }^{16}$ As Figure 5 shows, only after ten years has slower growth relative to a hypothetical continuation of balanced growth dissipated the initial increase in $U$ that results from liberalization. The following discussion of the Chilean experience with liberalization will suggest ways in which a more realistic unbalanced growth model could capture the welfare losses that appear to have taken place during Chile's transition period.

Chile is a country rich in natural resources that experienced a long period of primary-product export-led growth during the late nineteenth and early twentieth centuries. The Great Depression led to a collapse in the world prices of primary products and was a powerful stimulus to import-substituting industrialization in Chile and throughout Latin America. After World War II Chile, like virtually all other Latin American countries, adopted a policy of government-led import-substituting industrialization. In particular this meant prohibitive trade barriers to manufactured imports, though many other incentives for industrial investment were offered such as subsidized credit. This policy led to the creation of a highly diversified but inefficient manufacturing sector that could not compete in international markets. Per capita GDP during the period 1950-1973 grew at an average annual rate of about 2 percent (see Figure $6)$, slightly higher or lower depending on the data source. In late 1973 a new regime came to power and began a sweeping program of economic liberalization. After a sharp contraction in 1975, a boom that carried per capita GDP to a new peak in 1981 was followed by another sharp contraction in 1982-3. By 1984 per capita GDP was essentially

${ }^{16}$ No tariff revenue was lost as a result of liberalization because the tariff is prohibitive along the balanced growth path by assumption. 
back at its 1973 level (itself already down from the peak in 1971), hence the phrase "lost decade" of economic growth. Since 1984, however, per capita GDP has grown at an accelerating rate, with an annual average over the period 1984-1991 above four percent.

While most observers perceive the end of the boom after 1981 as caused by avoidable macroeconomic mismanagement (Edwards and Edwards 1987 is typical), I want to argue that the "lost decade" of economic growth was the natural outcome of a transition from balanced growth to unbalanced growth, the latter being led by agriculture and agro-processing industry. This larger picture was masked by the 1976-1981 boom, which appears to have been the result of a speculative bubble in finance and urban real estate. ${ }^{17}$ The macroeconomic mismanagement story correctly captures the jagged ups and downs shown in Figure 6 for per capita GDP during the period 1973-1984, but misses the connection between the medium to long term growth performance of the economy and the underlying structural transformation that began in 1973. It is partly the perception that this transformation has "taken root" that leads observers to see the current boom, unlike that during 1976-81, as sustainable.

In support of my reinterpretation of Chilean economic performance after 1973 I offer the evidence of Figures 7, 8, and 9. These figures show, respectively, that after 1973 there was: 1) a complete reversal of the historically declining trend in the ratio of agricultural to manufacturing GDP; 2) an explosion of agricultural exports and manufacturing imports, and 3) a rising import penetration ratio in manufacturing after one removes agro-processing industries, much of the output of which would be classified as agricultural if the Standard Industrial Trade Classification (SITC) was used. The trends predicted by the unbalanced growth model, obscured by the 1981 peak in demand for manufactures (both domestic and imported), are brought out by the estimated time trends included in

${ }^{17}$ Morandé (1992) reports that an index of the real price of housing in Santiago more than quadrupled from early 1976 to early 1981, then fell to its earlier level. Real stock prices experienced a similar boom and bust. 
the Figures. Clearly, however, there are ways in which the data do not fit the stylized story I am telling, which bring out several limitations in the ability of my simple model to describe the real world. First, we note that during the period through 1973 that I identify with balanced growth, Chile was a net importer of the products of agriculture, the sector I identify with sector $T$. The true source of foreign exchange for the Chilean economy was copper mining, not agriculture. The copper mining sector does not fit into the framework of my model because wide swings in the world price of copper dominate any productivity changes due to accumulation of knowledge and because its extremely low labor intensity minimizes the importance of its labor market interactions with other sectors. ${ }^{18}$ Second, a related point is that the ratio of agricultural to manufacturing production is in secular decline through 1973, while of course this ratio should be constant along a balanced growth path. This reflects not only government intervention on behalf of manufacturing over and above protection, but also the operation of Engel's law as incomes rose while (as shown in Figure 8) the Chilean agricultural and manufacturing sectors remained virtually closed to international trade. Third, and most important, the model of unbalanced growth implies that after liberalization the manufacturing sector will ultimately disappear completely. The limitation of the model revealed by this undoubtedly false prediction flows from the fact that all entrepreneurs/firms within a sector are identical, so if one ceases to invest and ultimately goes out of business so must all the others.

One more key feature of the Chilean liberalization experience that is left out by my market clearing model is the tremendous increase in unemployment that occurred: the unemployment rate averaged 4.5 percent during the period 1966-1972 but never dropped below 10 percent during the 1976-1981 "boom". ${ }^{10}$ This probably accounts for the fact that

${ }^{18}$ In 1973 the ratios of mining employment to manufacturing employent and agricultural employment were 16.9 and 15.4 percent, respectively (data supplied by Joseph Grunwald from computations by Esteban Jadresic).

${ }^{10}$ The sources for the unemployment data are Economic and Social Indicators and various issues of the Monthly Bulletin of the Central Bank of Chile. 
Chile did not merely experience a growth slowdown but an actual growth stoppage during the period 1974-1984. This suggests that it is the assumption of costless movement of labor between sectors that prevents my unbalanced growth model from capturing the "painfulness" of the Chilean liberalization experience.

\section{The effects of economic integration}

Consider two countries or regions with separate labor markets. The two countries or regions may be specialized in production of different goods which they trade with the rest of the world (including each other) at given world prices, or they may produce the same good but be unable to exchange entrepreneurs and information due to geographic distance or cultural and linguistic differences. Each country or region is on its own steady state growth path as described by the model of section 1.2 (omitting the intermediate good).

Now suppose the two countries or regions unite to become one country with free internal labor mobility. If the new country adopts a policy of free trade, so that the relative price of the regional outputs remains unchanged compared to the pre-integration situation, then (as noted in the previous section) we know that there exists a unique $\mathrm{k}^{* *}$ associated with this $\mathrm{p}^{* *}$ that yields balanced growth. (If the two regions produce the same good then $\mathrm{p}^{* *}$ is identically one, and if their knowledge acquisition technologies are also the same it is easily shown that $\mathrm{k}^{* *}$ equals one as well.) I also argucd in scction 3 that this balanced growth steady state is globally unstable. Thus we expect that under free trade one region will go into relative decline in the sense that its entrepreneurs will become progressively poorer relative to those in the other region and will employ a monotonically decreasing share of the new country's labor force. This implies continual emigration from the declining region even in the case where the two regions produce different goods if entrepreneurs in the booming region find that they need to continue to locate their production there in order to benefit from knowledge spillovers in their industry. 
Which region will ultimately dominate the integrated economy? To a void introducing new notation for the knowledge stock ratio and the terms of trade we label the regions $\mathrm{T}$ and $\mathrm{N}$. We can then say that region $\mathrm{T}(\mathrm{N})$ will dominate if the knowledge stock ratio $k$ at the time of integration is greater (less) than $k^{* *}$. It obviously follows that region $\mathrm{j}$ is more likely to dominate the greater is $\overline{\mathrm{K}}^{\mathrm{j}}$ at the time of integration. Since we already saw in Proposition 3.1 that $\mathrm{k}^{* *}$ increases with $\mathrm{p}^{* *}$, a region is also more likely to dominate the higher is the relative price of its output on world markets. Intuitively, a greater knowledge stock or better terms of trade both act to raise the absolute wage rate of a region, so that economic integration makes investment by that region's entrepreneurs more profitable when it causes the new wage rate to settle in between the two old ones. By a straightforward modification of the proof of Proposition 3.1 in the Appendix, the reader can show that $\mathrm{k}^{* *}$ increases (decreases) with $\gamma^{\mathrm{T}}$ and $\beta^{\mathrm{T}}\left(\gamma^{\mathrm{N}}\right.$ and $\left.\beta^{\mathrm{N}}\right)$, from which it can be deduced that a region is more likely to dominate the easier is its acquisition of knowledge. Again the intuition for this result runs through greater profitability of investment. While the possible asymmetry between the production functions for the outputs of the two regions prevents us from proving a Proposition, I have established a presumption that if, at the time of economic integration, one region has a wage rate and growth rate greater than or equal to those of the other region (with one strict inequality), that region's entrepreneurs will ultimately employ the entire labor force of the integrated economy. It is easy to construct examples where the region with the higher wage rate but lower growth rate or vice versa will not dominate, simply by manipulating the ratio of the region's labor force endowment to its entrepreneurial endowment. This ratio affects the absolute wage rate and the growth rate in opposite directions, but it becomes irrelevant to relative profitability after economic integration.

In the steady state the new country must grow faster than the region that came to dominate the economy did in isolation: economic integration has simply provided this region with a source of cheap labor, lowering the wage rate per unit of knowledge and 
thereby increasing profitability and the growth rate. It is nevertheless theoretically possible that this growth rate is lower than was the growth rate in isolation of the region that declined. Let us set aside this case and suppose that in its steady state the new country grows faster than did either of its component regions in isolation. Following the analysis of liberalization in the previous section, immediately after economic integration the new country may nevertheless grow slower than did either region in isolation if, for example, the declining region was sufficiently larger than the booming region. Also as in the case of liberalization, the welfare effect of any initial slower growth due to economic integration may be more than offset by an initial efficiency gain, which now results from the integration of two previously separate labor markets.

If it is the case that the two regions are specialized in producing different goods, suppose that the quantity supplied of the output of the region that would decline under free trade is smaller than the quantity demanded by the new country at the initial world price ratio. It is then possible for a policy such as a common external tariff to allow the relative price of that output to rise above the world price sufficiently to permit convergence to the balanced growth path described in Table 1 . How will the steady state growth rate compare to the growth rates of the two regions in isolation? This is unclear since there need not be any cheap labor effect: from the point of view of either region both labor supply and competing labor demand are being added by economic integration. In fact, I have constructed numerical examples where the new steady state growth rate is in between the old regional growth rates, where it is above both old growth rates, and where it is below both old growth rates. Of course we do know that the new country must grow slower along the balanced growth path than it would have if it had been allowed to specialize in the output of the region that would have dominated under free trade. It therefore appears that in the choice between free trade, yielding an unbalanced growth path, and protection, yielding a balanced growth path, the new country must trade off regional equity against not only static but also dynamic efficiency. 
It is interesting to view the much-studied problems of the South of Italy in light of the discussion in this section. It is generally agreed that per capita output was lower in the South than in the North of Italy when the country was unified in 1861. At that time the tariffs between the various Italian states were eliminated and low Piedmontese external tariffs were substituted for the much higher external tariffs of the Kingdom of the Two Sicilies (the South). In line with the discussion above, let us think of the North and South of Italy in 1861 as two regions that produce the same good but are unable to exchange entrepreneurs and information. Given the initial difference in per capita output and the closer proximity of the North to Northwest Europe, the source of the most advanced technological knowledge at the time (effectively giving the North a superior knowledge acquisition technology), it is reasonable to assume that the ratio of the Northern to Southern knowledge stock exceeded $\mathbf{k}^{* *}$ at the time of Unification. My model then predicts that a process of unbalanced growth should have begun, with continual migration of the Southern labor force to the North and decline in Southern per capita income relative to the North. These events did indeed take place, but there is considerable debate over their timing. The censes of 1861,1881 , and 1901 show a faster rise in industrial employment in the South than in the North up to 1881 , followed by a sharp fall in Southern industrial employment versus a continued increase in the North. King (1985, pp. 35-37) believes a relative decline in Southern industrial employment began immediately but was masked by a "rogue" census in 1881. Allen and MacLennan (1970, pp. 37-38) argue that the Southern economy was relatively isolated until the mid-1880s, when the new State's program of bringing the Southern road and railway network up to Northern standards began to bear fruit, after which time the regional product and labor markets were more integrated and the Southern decline began. But in any case, no significant decline in relative Southern income was measured until after 1901, simply because neither region registered significant per capita income growth before then. From 1901 to 1951 , however, several different statistical sources all support the occurrence of a more or less monotonic decline in relative 
Southern income. ${ }^{20}$ According to Allen and MacLennan (1970, p. 40) virtually the entire increase in Italy's agricultural output between 1900 and 1940 occurred in the North, and industrial employment declined by about 10 percent between 1901 and 1936 in the South but grew by roughly 50 percent in the North.

Since 1950, massive government transfers from the North to the South have allowed the lat ter to keep pace with or even catch up slightly to the former in terms of per capita GDP (OECD 1990, p. 70). Migration from the South to the North was nevertheless about two million between 1951 and 1961 and again between 1961 and 1971, 600,000 between 1971 and 1981 and 100,000 between 1982 and 1988 (OECD 1990, p. 76, n. 38). The clear slowdown in migration does not appear to reflect greater employment generation in the South since the Southern unemployment rate rose to over 20 percent in 1988 , more than three times the level in the North (OECD 1990, p. 71). Modernization and growth has definitely taken place in the South since 1950, but Northern entrepreneurs have been the agents of this progress according to the literature surveyed by King (1987, pp. 191-192). This indicates a gradual overcoming of the barriers of geographic distance, culture and language that originally prevented the interregional mobility of entrepreneurs and information, so that in terms of the discussion of this section the movement of the Italian economy towards a steady state where Northern entrepreneurs employ the entire labor force need not imply the emptying of the South in the long run.

\section{Summary and conclusions: Application to the transition in Eastern Europe?}

In this paper a mechanism of endogenous growth suitable for investigation of sectoral or regional interaction was developed. It was shown how the high value placed on production linkages by economic historians might be reconciled with the high value placed on openness (often implying lack of linkages) by observers of contemporary less developed

${ }^{20}$ See the sources cited in OECD (1990, p. 64, n. 24) and Allen and MacLennan (1970, p. 39, ก. 1). 
countries. When the output of one sector is traded and the output of the other is nontraded, it was shown how the traded goods sector acts as the "engine of growth" in the sense that its profitability of knowledge acquisition primarily determines the steady state aggregate growth rate. It was also shown how sectors or regions interact out of steady state through product, labor, and capital markets, and in particular how if the former interaction dominates the growth of one sector "pulls along" the growth of the other while if the latter two interactions dominate one sector or region booms while the other declines. The paper built on these results to show why liberalization of foreign trade should lead to a transition from a lower to a higher steady state growth rate and why, during the course of this transition, growth might initially be even slower than before liberalization. A final application to economic integration of previously separate regions or countries showed that the largest growth effects are to be had if one region is allowed to decline and provide a source of cheap labor for the other region.

One way in which the theory developed in this paper could be profitably extended is by developing the spatial implications of the balanced growth model in the case where transportation costs cause the output of sector $\mathrm{N}$ to be nontraded. The spatial boundary of tradeability could be determined endogenously, thereby defining a region within the country. If this region is growing faster than the rest of the country a spatial agglomeration at the regional level could result that is reminiscent of that described by Krugman (1991) but is driven by a leading, technologically progressive industry as in Perroux (1955).

A more speculative extension of the theory developed in this paper would be application of the unbalanced growth model to the transition from state socialism to capitalism. McMillan and Naughton (1992) argue that the immediate acceleration of growth that followed reform in China compared to the depression that accompanied the transition in much of Eastern Europe indicates the advantage of "evolutionary" over "big-bang" reform. They point to three key factors in China's reform success (p. 131): 
"Eirst, massive entry of non-state firms; second, a dramatic increase in competition, both among state firms and between state firms and non-state firms; and, third, improvements in the performance of state-owned firms resulting from state-imposed market-like incentives." Let us interpret sectors $\mathrm{T}$ and $\mathrm{N}$ in section 3 above as the non-state sector and state enterprise sector, respectively. Entrepreneurs in the non-state sector acquire knowledge in order to better meet the needs of the market while "entrepreneurs" (manager-bureaucrats) in the state sector acquire knowledge in order to better meet the needs of the state plan. In a "big-bang" liberalization further acquisition of the latter type of knowledge is useless and the incumbent managers of state enterprises are unqualified to acquire the former type of knowledge, hence investment on the part of state enterprises dries up. Since the state sector is by far the larger sector initially, growth plummets and could even turn negative if we allowed for costly movement of labor between the state and non-state sectors. With an evolutionary liberalization of the type undertaken by China, on the other hand, the state plan is gradually adjusted to become more "market-like" and state enterprise managers either learn how to respond to the new incentives or are replaced by people who are able to learn how, and in the limit they are not at a disadvantage relative to non-state sector entrepreneurs with regard to further knowledge acquisition and investment. State enterprises and non-state enterprises can then be viewed simply as firms of different size within a unified economy, and there is no reason for investment to collapse in either "sector". In short, the evolutionary reform policies followed by China work to maintain investment by state enterprises, which is necessary to avoid a transitional depression because the state sector is initially so much larger than the non-state sector. 


\section{APPENDLX}

A0. Assumptions on second derivatives of the profit functions derived in section 2

Throughout this Appendix we will need assumptions on the second derivatives of our profit functions that are stronger than the restrictions implied by the convexity property we get from standard microeconomic theory. For example, convexity tells us that the second derivative with respect to the price of output is nonnegative, so that output supply functions are not downward-sloping, but we need to assume that output supply functions are strictly upward-sloping, implying that this second derivative is positive. All of the assumptions made here are satisfied if, for example, the underlying production functions are Cobb-Douglas, as they are in all of the simulations conducted in the text. ASSUMPTION A0.1: $\Pi_{11}^{j}>0, j=T, N$.

This is true if and only if the supply functions are upward-sloping. ASSUMPTION A0.2: $\Pi \Pi_{j_{2}}>0, j=T, N$.

This is true if and only if the input demand functions are downward-sloping. ASSUMPTION A0.3: $\Pi_{12}^{j}\left(=\Pi_{21}^{j}\right)<0, j=T, N$.

This is true if and only if a marginal increase in knowledge increases input demand, or equivalently if and only if an increase in input price reduces the marginal profit from an additional unit of knowledge.

A1. Uniqueness and comparative statics with exogenous terms of trade Proof of uniqueness. I first demonstrate uniqueness of $\mathrm{g}^{* *}$ and $\mathrm{r}^{* *}$ by showing that Figure 1 applies, i.e., that the two entrepreneurial first-order conditions and the labor-market clearing condition yield $g$ varying inversely with $r$. We totally differentiate the appropriate equations from Table 1 to obtain 


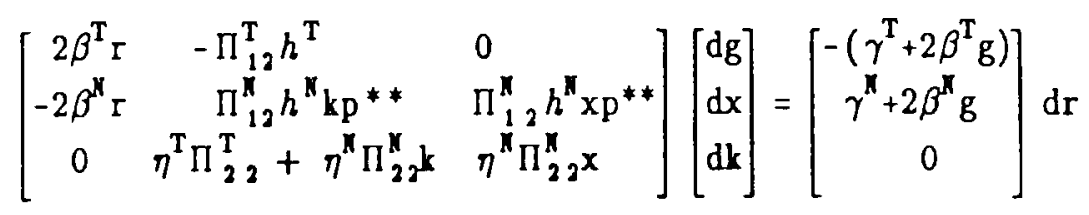

Using the assumptions in section A0 the reader can easily show that the determinant of the left-hand matrix is positive. Substituting the right-hand column for the first column of this matrix, we obtain a new matrix whose determinant is easily shown to be negative. From Cramer's rule, it follows that $\mathrm{dg} / \mathrm{dr}<0$ and Figure 1 applies. I next show that given the unique $g^{* *}$ and $r^{* *}$, a unique $x^{* *}$ and $k^{* *}$ are determined. This follows if and only if the equation

$$
\Pi_{1}^{\mathrm{T}}\left(\mathrm{h}^{\mathrm{T}}, \mathrm{x}\right) h^{\mathrm{T}} /\left(\gamma^{\mathrm{T}}+2 \beta^{\mathrm{T}} \mathrm{g}^{* *}\right)=\Pi_{1}^{\mathrm{N}}\left(\mathrm{p}^{* *} \mathrm{~h}^{\mathrm{N}}, \mathrm{kx}\right) h^{\mathrm{N}} \mathrm{p}^{* *} /\left(\gamma^{\mathrm{N}}+2 \beta^{\mathrm{N}} \mathrm{g}^{* *}\right)
$$

and the labor market clearing equation have a unique solution. A sufficient condition for uniqueness of this solution is that all principal submatrices of the associated Jacobian matrix have positive determinants (see Gale and Nikaido, 1965). Totally differentiating with respect to $\mathrm{k}$ and $\mathrm{x}$ yields the Jacobian

$$
\mathrm{J} 1=\left[\begin{array}{cc}
-\Pi_{12}^{N} h^{N} \times p^{* *} /\left(\gamma^{M}+2 \beta^{N} \mathrm{~g}^{* *}\right) & \Pi^{\mathrm{T}} h^{\mathrm{T}} /\left(\gamma^{\mathrm{T}}+2 \beta^{\mathrm{T}} \mathrm{g}^{* *}\right)-\Pi_{12}^{\mathrm{N}} h^{\mathrm{N}} \mathrm{kp}^{* *} /\left(\gamma^{\mathrm{N}}+2 \beta^{\mathrm{N}} \mathrm{g}^{* *}\right) \\
\eta^{\mathrm{N}} \Pi_{22}^{\mathrm{N}} \mathrm{x} & \eta^{\mathrm{T}} \Pi_{22}^{\mathrm{T}}+\eta^{N} \Pi_{22}^{\mathrm{N}} \mathrm{k}
\end{array}\right]
$$

The diagonal terms of $\mathrm{Jl}$ are positive and it is easily shown that its determinant is as well. Proof of Proposition 3.1. Total differentiation of the first four equations in Table 1 yields

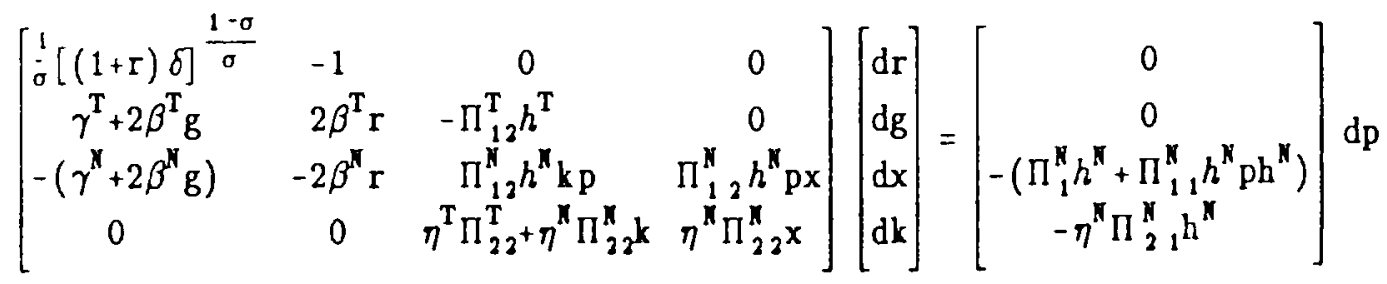


Using the assumptions in section A0 the reader can easily show that the determinant of the left-hand matrix is positive. Substituting the right-hand column for the fourth column of this matrix, we obtain a new matrix whose determinant is unambiguously positive provided that $\eta^{\mathrm{N}} \Pi_{22}^{\mathrm{N}} \mathrm{k} \Pi_{11}^{\mathrm{N}} h^{\mathrm{N}} \mathrm{ph}^{\mathrm{N}}-\Pi_{12}^{\mathrm{N}} h^{\mathrm{N}} \mathrm{kp} \eta^{\mathrm{N}} \Pi_{21}^{\mathrm{N}} h^{\mathrm{N}} \geq 0$. But it follows from homogeneity of degree one of $\Pi^{j}$ in its two arguments that $\Pi_{11}^{j} \Pi_{22}^{j}-\Pi_{12}^{j} \Pi_{21}^{j}=0$. From Cramer's rule, we therefore have $\mathrm{d} k / \mathrm{d} p>0$.

A2. Uniqueness and comparative statics with endogenous terms of trade Conditions for uniqueness of the steady state growth rate and interest rate. Total differentiation of the last four equations in Table 1 yields

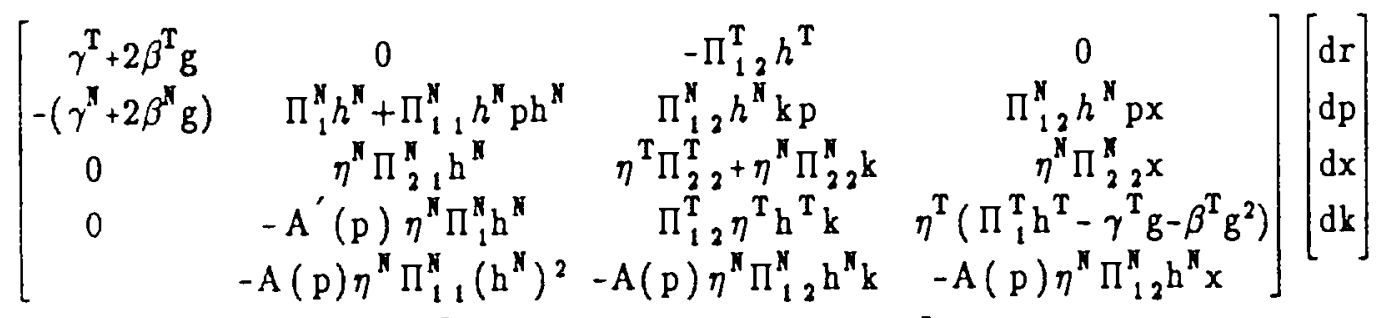

$$
\begin{aligned}
& =\left[\begin{array}{c}
-2 \beta^{\mathrm{T}} \mathrm{r} \\
2 \beta^{\mathrm{N}} \mathrm{r} \\
0 \\
\eta^{\mathrm{T}} \mathrm{k}\left(\gamma^{\mathrm{T}}+2 \beta^{\mathrm{T}} \mathrm{g}\right)+\eta^{\mathrm{I}}\left(\gamma^{\mathrm{N}}+2 \beta^{\mathrm{N}} \mathrm{g}\right)
\end{array}\right] \mathrm{dg}
\end{aligned}
$$

Using the assumptions in Section A0, the last equation in Table 1, and the facts $\Pi_{21}^{N} \Pi_{12}^{N}-\Pi_{11}^{N} \Pi_{22}^{N}=0, \Pi_{21}^{N} p^{N}+\Pi_{22}^{N} k x=0$, it is straightforward to verify that the determinant $\Delta$ of the left-hand matrix is positive if $A(p)-A^{\prime}(p) p \geq 0$. Substituting the right-hand column for the first column of this matrix, we obtain a new matrix whose determinant is equal to $-2 \beta^{\mathrm{T}} \Delta_{11}-2 \beta^{\mathrm{N}} \Delta_{21}-\left[\eta^{\mathrm{T}} \mathrm{k}\left(\gamma^{\mathrm{T}}+2 \beta^{\mathrm{T}} \mathrm{g}\right)+\eta^{\mathrm{N}}\left(\gamma^{\mathrm{N}}+2 \beta^{\mathrm{N}} \mathrm{g}\right)\right] \Delta_{11}$, where $\Delta_{i j}$ is the $(i, j)$ minor of the original matrix. Using the same information as before, it is easy to show that $\Delta_{11}$ and $\Delta_{21}$ are positive if $A(p)-A^{\prime}(p) p \geq 0$, but $\Delta_{11}$ is negative. It 
follows that the direct effect of $g$ on $r$ through the optimal investment decision, equal to $\left(-2 \beta^{\mathrm{T}} \mathrm{r} \Delta_{11}-2 \beta^{\mathrm{N}} \mathrm{r} \Delta_{31}\right) / \Delta$, is negative, and that the indirect effect of $\mathrm{g}$ on $\mathrm{r}$ through the nontraded goods market clearing condition, equal to $-\left[\eta^{\mathrm{T}} \mathrm{k}\left(\gamma^{\mathrm{T}}+2 \beta^{\mathrm{T}} \mathrm{g}\right)+\eta^{\mathrm{N}}\left(\gamma^{\mathrm{N}}+2 \beta^{\mathrm{N}} \mathrm{g}\right)\right] \Delta_{1} / \Delta$, is positive. If the direct effect dominates the indirect effect, an increase in $g$ will cause a decrease in $r$, and the latter four equations in Table 1 determine a downward-sloping curve in Figure 1, proving the uniqueness of the steady state growth rate and interest rate.

Proofs of Propositions 2.1.1-2.1.5: I again totally differentiate the last four equations in Table 1 to obtain

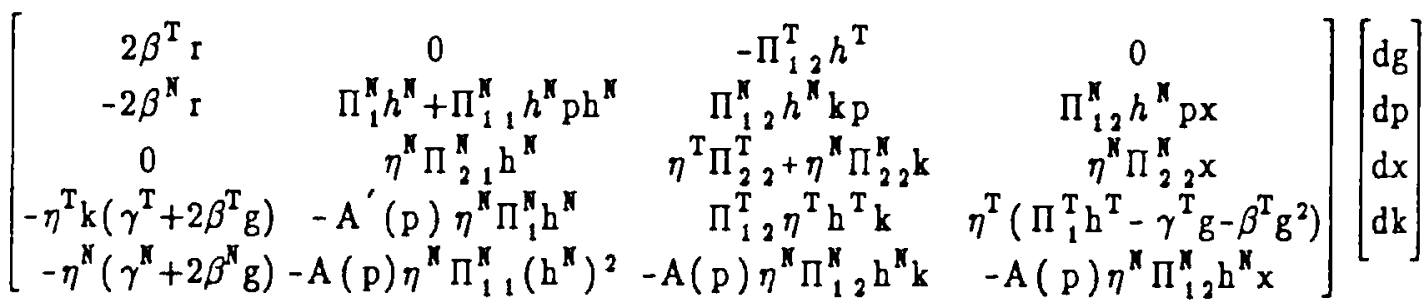

$$
\begin{aligned}
& =\left[\begin{array}{ccccc}
0 & -\mathrm{r} & -2 \mathrm{rg} & 0 & 0 \\
0 & 0 & 0 & \mathrm{r} & 2 \mathrm{rg} \\
-1 & 0 & 0 & 0 & 0 \\
0 & \eta^{\mathrm{T}} \mathrm{kg} & \eta^{\mathrm{T}} \mathrm{k}(\mathrm{g})^{2} & \eta^{\mathrm{X}} \mathrm{g} & \eta^{\mathrm{X}}(\mathrm{g})^{2}
\end{array}\right]\left[\begin{array}{l}
\mathrm{d} \overline{\mathrm{L}} \\
\mathrm{d} \gamma^{\mathrm{T}} \\
\mathrm{d} \beta^{\mathrm{T}} \\
\mathrm{d} \gamma^{\mathrm{X}} \\
\mathrm{d} \beta^{\mathrm{X}}
\end{array}\right]
\end{aligned}
$$

The assumption that the direct effect dominates the indirect effect of $g$ on $r$ implies that the determinant of the left-hand matrix is positive. Therefore, to prove Propositions 2.1.1-2.1.5 all we need to do is substitute the appropriate column of the right-hand matrix for the first column of the left-hand matrix and examine the sign of the determinant of the new matrix.

Proposition 2.1.1: Substituting the first column of the right-hand matrix, the determinant of the new matrix is $-\Delta_{31}$, where $\Delta_{i j}$ is the $(i, j)$ minor of the original left-hand matrix. Simple algebra shows that $-\Delta_{31}$ is positive if $A(p)-A^{\prime}(p) p \geq 0$. 
Proposition 2.1.2: Substituting the second column of the right-hand matrix, the determinant of the new matrix is $-r \Delta_{11}-\eta^{\mathrm{T}} \mathrm{kg} \Delta_{41}$. Using $\Pi_{12}^{\mathrm{N}} \Pi_{21}^{\mathrm{N}}-\Pi_{11}^{\mathrm{N}} \Pi_{22}^{\mathrm{N}}=0$ again, simple algebraic manipulation leads to the conclusion that $-\mathrm{r} \Delta_{11}-\eta^{\mathrm{T}} \mathrm{kg} \Delta_{41}$ is negative if $A(p)-A^{\prime}(p) p \geq 0$ and $r \geq g h^{T} / h^{T}$.

Proposition 2.1.3: Substituting the third column of the right-hand matrix, the determinant of the new matrix is $-2 \operatorname{rg} \Delta_{11}-\eta^{\mathrm{T}} \mathrm{k}(\mathrm{g})^{2} \Delta_{11}$. Let $\hat{\mathrm{I}}=2 \mathrm{rg}$ and $\hat{\mathrm{g}}=(\mathrm{g})^{2}$. By the proof of Proposition 2.1.2, we know that the determinant is negative if $A(p)-A^{\prime}(p) p \geq 0$ and $\hat{\mathrm{r}} \geq \hat{\mathrm{g}} h^{\mathrm{T}} / \mathrm{h}^{\mathrm{T}}$, or $2 \mathrm{rg} \geq(\mathrm{g})^{2} h^{\mathrm{T}} / \mathrm{h}^{\mathrm{T}}$ or $\mathrm{r} \geq \mathrm{g} h^{\mathrm{T}} / 2 \mathrm{~h}^{\mathrm{T}}$.

Proposition 2.1.4: Substituting the fourth column of the right-hand matrix, the determinant of the new matrix is $-r \Delta_{21}-\eta^{N} g \Delta_{41}$. Using the last equation in Table 1 and $\Pi_{21}^{\mathrm{N}} \mathrm{ph}^{\mathrm{N}}+\Pi_{2{ }_{2}}^{\mathrm{N}} \mathrm{kx}=0$ again, this determinant reduces to $-\Pi_{12}^{\mathrm{T}} h^{\mathrm{T}} \eta^{\mathrm{N}} \Pi_{22}^{\mathrm{N}} \times\left\{h^{\mathrm{N}} \Pi_{1}^{\mathrm{N}} \eta^{\mathrm{N}} \mathrm{g}-(\mathrm{r} / \mathrm{p}) \eta^{\mathrm{N}}\left[\gamma^{\mathrm{N}} \mathrm{g}+\beta^{\mathrm{N}}(\mathrm{g})^{2}\right]\right\}$ in the case where $\mathrm{U}\left(\mathrm{c}_{\mathrm{t}}^{\mathrm{T}}, \mathrm{c}_{\mathrm{t}}^{\mathrm{N}}\right)$ is Cobb-Douglas so that $A(p)-A^{\prime}(p) p=0$. Using the third equation in Table 1 to simplify this expression yields $-\Pi_{12}^{\mathrm{T}} h^{\mathrm{T}}\left(\eta^{\mathrm{N}}\right)^{2} \Pi_{22}^{\mathrm{N}} \mathrm{xr} \beta^{\mathrm{N}}(\mathrm{g})^{2} / \mathrm{p}$, which is positive under the assumptions in Section $\mathrm{A} 0$ and approaches zero as $\beta^{\mathrm{N}}$ approaches zero.

Proposition 2.1.5: Substituting the fifth column of the right-hand matrix and following the same manipulations as in the proof of Proposition 2.1.4 thereafter reduces the resulting determinant to $-\Pi_{12}^{\mathrm{T}} h^{\mathrm{T}} \eta^{\mathrm{N}} \Pi_{22}^{\mathrm{N}} \mathrm{x}\left\{h^{\mathrm{N}} \Pi_{1}^{\mathrm{N}} \eta^{\mathrm{N}}(\mathrm{g})^{2}-(2 \mathrm{rg} / \mathrm{p}) \eta^{\mathrm{N}}\left[\gamma^{\mathrm{N}} \mathrm{g}+\beta^{\mathrm{N}}(\mathrm{g})^{2}\right]\right\}$ in the case where $U\left(c_{b}^{T}, c_{l}^{N}\right)$ is Cobb-Douglas. Again, using the third equation in Table 1 to simplify this expression yields $\Pi_{12}^{\mathrm{T}} h^{\mathrm{T}}\left(\eta^{\mathrm{N}}\right)^{2} \Pi_{22}^{\mathrm{N}} \mathrm{xr} \gamma^{\mathrm{N}}(\mathrm{g})^{2} / \mathrm{p}$, which is negative under the assumptions in Section $A 0$ and approaches zero as $\gamma^{\mathbf{N}}$ approaches zero.

Proof that $p * k *$, and $x *$ are all uniquely determined given $g *$ and $r *$ under the sufficient condition $A(p)-A^{\prime}(p) p \geq 0$. This follows if and only if the equation

$$
\Pi_{1}^{\mathrm{N}}\left(\mathrm{ph}^{\mathrm{N}}, \mathrm{kx}\right) h^{\mathrm{N}} \mathrm{p}\left(\gamma^{\mathrm{T}}+2 \beta^{\mathrm{T}} \mathrm{g}^{*}\right)-\Pi_{1}^{\mathrm{T}}\left(\mathrm{h}^{\mathrm{T}}, \mathrm{x}\right) h^{\mathrm{T}}\left(\gamma^{\mathrm{N}}+2 \beta^{\mathrm{N}} \mathrm{g}^{*}\right)=0
$$

and the labor market and nontraded goods market clearing equations have a unique solution. Totally differentiating with respect to $p, x$, and $\mathbf{k}$ yields the Jacobian 


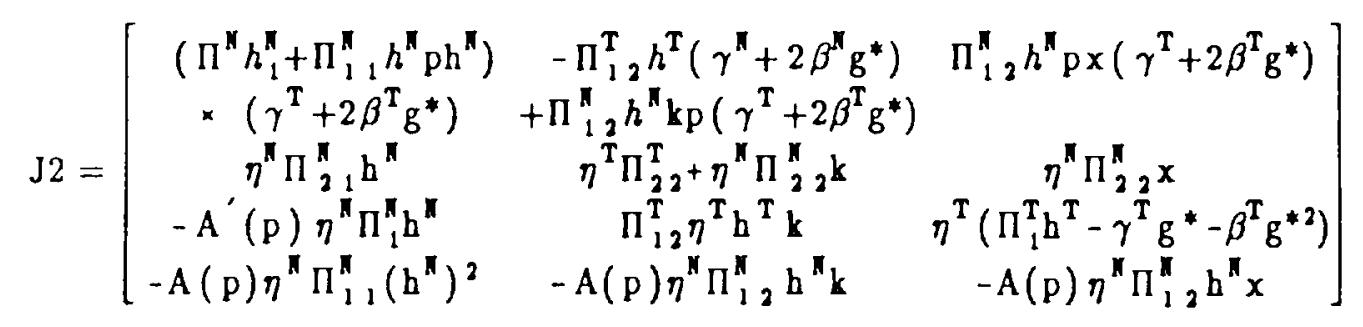

The diagonal terms of $\mathrm{J} 2$ are positive. Simple algebra shows that the determinants of the lower right-hand and upper left-hand principal submatrices are also positive. The determinant of the principal submatrix formed by deleting the second row and second column of $\mathrm{J} 2$ is easily shown to be positive if $A(p)-A^{\prime}(p) p \geq 0$. Finally, the determinant of $\mathrm{J} 2$ can be shown to be positive if $A(p)-A^{\prime}(p) p \geq 0$ by repeated use of the fact $\Pi_{12}^{N} \Pi_{21}^{N}-\Pi_{11}^{N} \Pi_{22}^{N}=0$ and by using equation $\left(A 1^{\prime}\right)$ and the last equation in Table 1. Proof of Proposition 2.1.6. I will write out the proof for the increase in $\gamma^{\mathrm{N}}$. The proof for the increase in $\beta^{\mathrm{N}}$ is qualitatively identical. First note that under the assumptions that $\mathrm{U}\left(\mathrm{c}_{\mathfrak{l}}^{\mathrm{T}}, \mathrm{c}_{\imath}^{\mathrm{N}}\right)$ is Cobb-Douglas and $\beta^{\mathrm{N}}$ equals zero, $\mathrm{g}^{*}$ is unchanged by an increase in $\gamma^{N}$ by Proposition 2.1.4. If follows that $r^{*}$ is also unchanged, so we can do the comparative static analysis using only equation ( $\left.\mathrm{Al}^{\prime}\right)$ and the last two equations in Table 1. Total differentiation yields $\mathrm{J} 2 \mid \beta^{\mathrm{N}}=0 \times[\mathrm{dpdxdk}]=\left[\Pi_{1}^{\mathrm{T}} h^{\mathrm{T}} 0 \eta^{\mathrm{N}} \mathrm{g}^{*}\right] \times \mathrm{d} \gamma^{\mathrm{N}}$. The determinant of $\mathrm{J} 2 \mid \beta^{\mathrm{N}}=0$ can be shown to be positive using the proof of uniqueness immediately above. To complete the proof we then need only to substitute $\left[\Pi_{1}^{\mathrm{T}} h^{\mathrm{T}} 0 \eta^{\mathrm{N}}\right]$ for the first column of $\mathrm{J} 2 \mid \beta^{N}=0$ and examine the sign of the determinant of the new matrix. This can be shown to be positive using simple algebra. Note that since $\mathrm{g}^{*}$ is unchanged, $\mathrm{x}^{*}$ is fixed by the second equation in Table 1 . It is then clear from the last equation in Table 1 that $\mathrm{k}^{*}$ must increase to offset the increase in $\mathrm{p}^{*}$ and $\gamma^{\mathrm{N}}$ or $\beta^{\mathrm{N}}$. 
References

Ahluwalia, Isher Judge, and C. Rangarajan. "A Study of Linkages between Agriculture and Industry: the Indian Experience." In The Balance Between Industry and Agriculture in Economic Development, Proceedings of the Eighth World Congress of the International Economic Association, Delhi, India, 1986. New York: St. Martin's, 1988.

Allen, Kevin, and M. C. MacLennan. Regional Problems and Policies in Italy and France. London: George Allen and Unwin, 1970.

Anderson, Dennis, and Farida Khambata. "Small Enterprises and Development Policy in the Philippines: A Case Study." World Bank Staff Working Paper No. 468, 1981.

Baldwin, Robert E. "Export Technology and Development from a Subsistence Level." Economic Journal 73 (March 1963): 80-92.

Baer, Werner. The Brazilian Economy: Growth and Development. New York: Praeger, 1989.

Chadha, G. K. The State and Rural Economic Transformation: The Case of Punjab 1950-1985. New Delhi: Sage Publications, 1986.

Child, Frank C., and Hiromitsu Kaneda. "Links to the Green Revolution: A Study of Small-Scale, Agriculturally Related Industry in the Pakistan Punjab." Economic Development and Cultural Change (January 1975): 249-275.

Edwards, Sebastian. "Trade Orientation, Distortions, and Growth in Developing Countries." Journal of Development Economics 39 (July 1992): 31-57.

Edwards, Sebastian, and Alejandra Cox Edwards. Monetarism and Liberalization: the Chilean Experiment. Cambridge: Ballinger, 1987.

Gale, David and Hukukane Nikaido. "The Jacobian Matrix and Global Univalence of Mappings." Mathematische Annalen 159 (1965): 81-93.

Grossman, Gene, and Elhanan Helpman. "Hysteresis in the Trade Pattern." NBER Working Paper No. 3526, December 1990.

Grossman, Gene, and Elhanan Helpman. Innovation and Growth in the Global Economy. Cambridge: MIT Press, 1991.

Hirschman, Albert. The Strategy of Economic Development. New Haven: Yale University Press, 1958.

King, Russell. The Industrial Geography of Italy. New York: St. Martin's, 1985.

King, Russell. Italy. London: Harper and Row, 1987. 
Krugman, Paul R. Geography and Trade. Cambridge: MIT Press, 1991.

Lucas, Robert E. "On the Mechanics of Economic Development." Journal of Monetary Economics 22 (July 1988): 3-42.

McMillan, John, and Barry Naughton. "How to Reform a Planned Economy: Lessons from China." Oxford Review of Economic Policy 8 (Spring 1992): 130-143.

Matsuyama, Kiminori. "Agricultural Productivity, Comparative Advantage, and Economic Growth." Northwestern Discussion Paper No. 934, May 1991.

Morandé, Felipe. "The Dynamics of Real Asset Prices, the Real Exchange Rate, Trade Reforms, and Foreign Capital Inflows: Chile, 1976-1989." Joumal of Development Economics 39 (July 1992): 111-139.

Murphy, Kevin M., Andrei Shleifer, and Robert Vishny. "Income Distribution, Market Size, and Industrialization." Quarterly Journal of Economics 104 (August 1989): $537-564$.

Nicholls, William M. "Industrial-Urban Development as a Dynamic Force in Transforming Brazilian Agriculture, 1940-1950." In Erik Thorbecke, ed., The Role of Agriculture in Economic Development. New York: National Bureau of Economic Research, 1969.

Nishimizu, Mieko, and John M. Page, Jr. "Productivity Change and Growth in Industry and Agriculture: An International Comparison." In The Balance Between Industry and Agriculture in Economic Development, Proceedings of the Eighth World Congress of the International Economic Association, Delhi, India, 1986. New York: St. Martin's, 1988.

OECD. OECD Economic Surveys: Italy. Paris: OECD, 1990.

Pack, Howard, and Larry E. Westphal. "Industrial Strategy and Technological Change: Theory versus Reality." Joumal of Development Economics 22 (June 1986): $87-128$.

Perroux, François. "Note sur la Notion de 'Pôle de Croissance'." Economie Appliquée (January-June 1955): 307-320.

Ranis, Gustav, and John C. H. Fei. "A Theory of Economic Development." American Economic Review 51 (September 1961): 533-565.

Rauch, James E. "Balanced and Unbalanced Growth." University of California, San Diego Discussion Paper 92-28 (August 1992).

Rebelo, Sergio. "Long-Run Policy Analysis and Long-Run Growth." Journal of Political Economy 99 (June 1991): 500-521.

Resnick, Stephen. "The Decline of Rural Industry Under Export Expansion: A Comparison among Burma, Philippines, and Thailand, 1870-1938." Journal of Economic History 30 (March 1970): 51-73. 
Riedel, James. "A Balanced Growth Version of the Linkage Hypothesis: Comment." Quarterly Journal of Economics 90 (May 1976): 319-322.

Romer, Paul M. "Crazy Explanations for the Productivity Slowdown." NBER Macroeconomics Annual 1987: 163-202.

. 1989. "Capital Accumulation in the Theory of Long Run Growth." In Robert J. Barro, ed., Modern Business Cycle Theory. Cambridge: Harvard University Press, 1989.

Stewart, Frances and Ejaz Ghani. "How Significant are Externalities for Development?" World Development 19 (June 1991): 569-594.

Tang, Anthony. Economic Development in the Southern Piedmont. Chapel Hill: University of North Carolina, 1958.

Teece, David J. The Multinational Corporation and the Resource Cost of Technology Transfer. Cambridge, MA: Ballinger, 1976. 


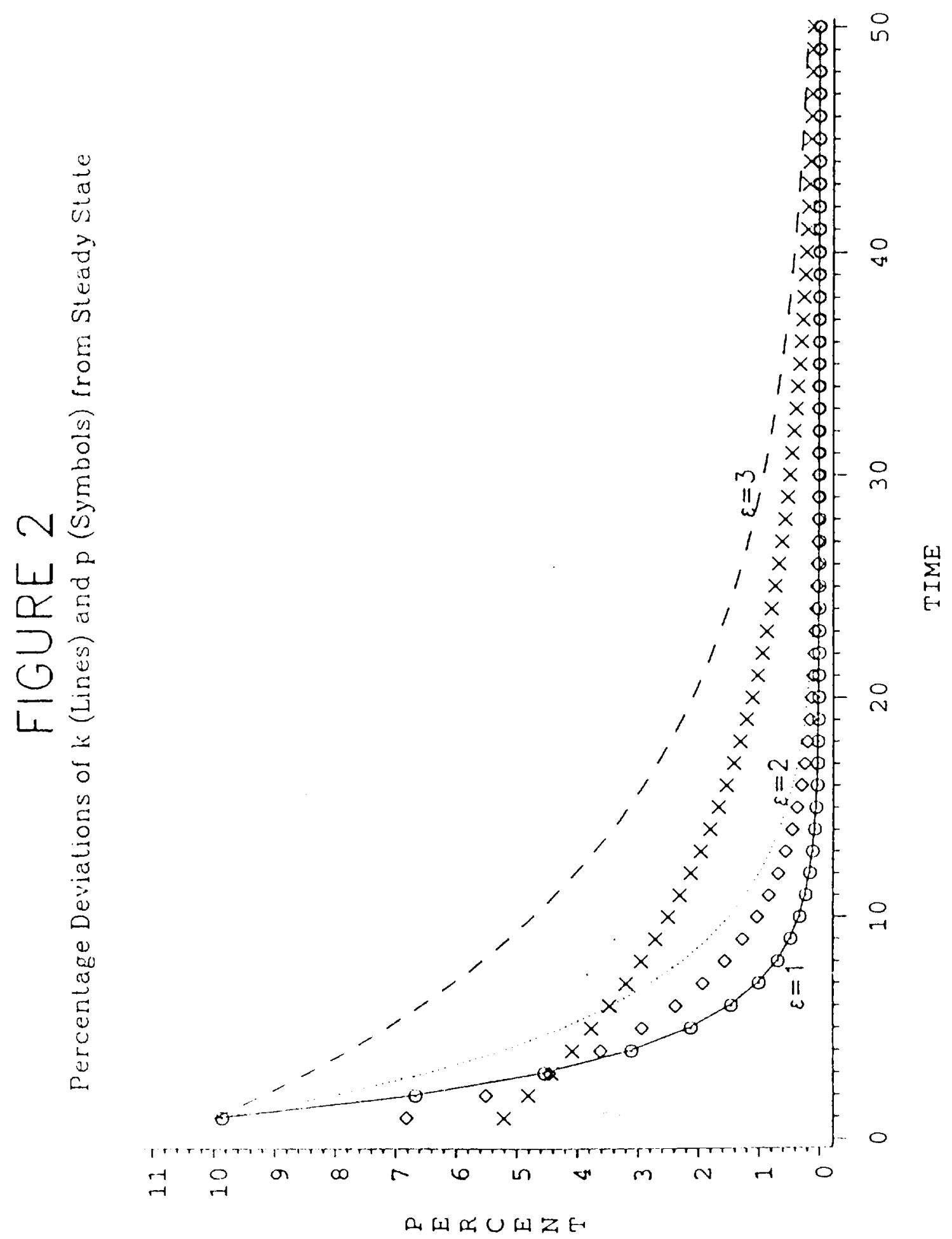




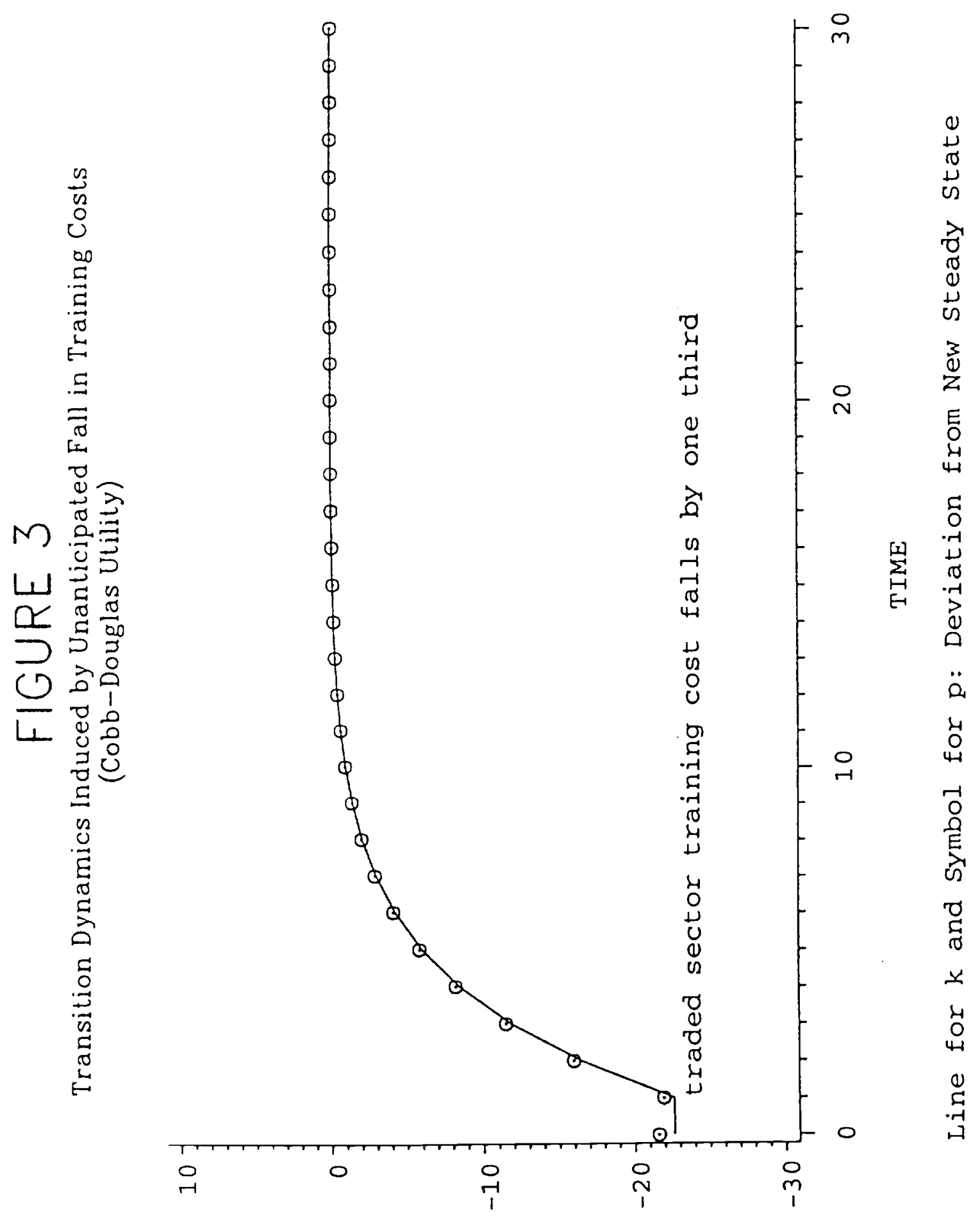

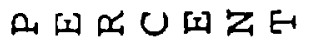




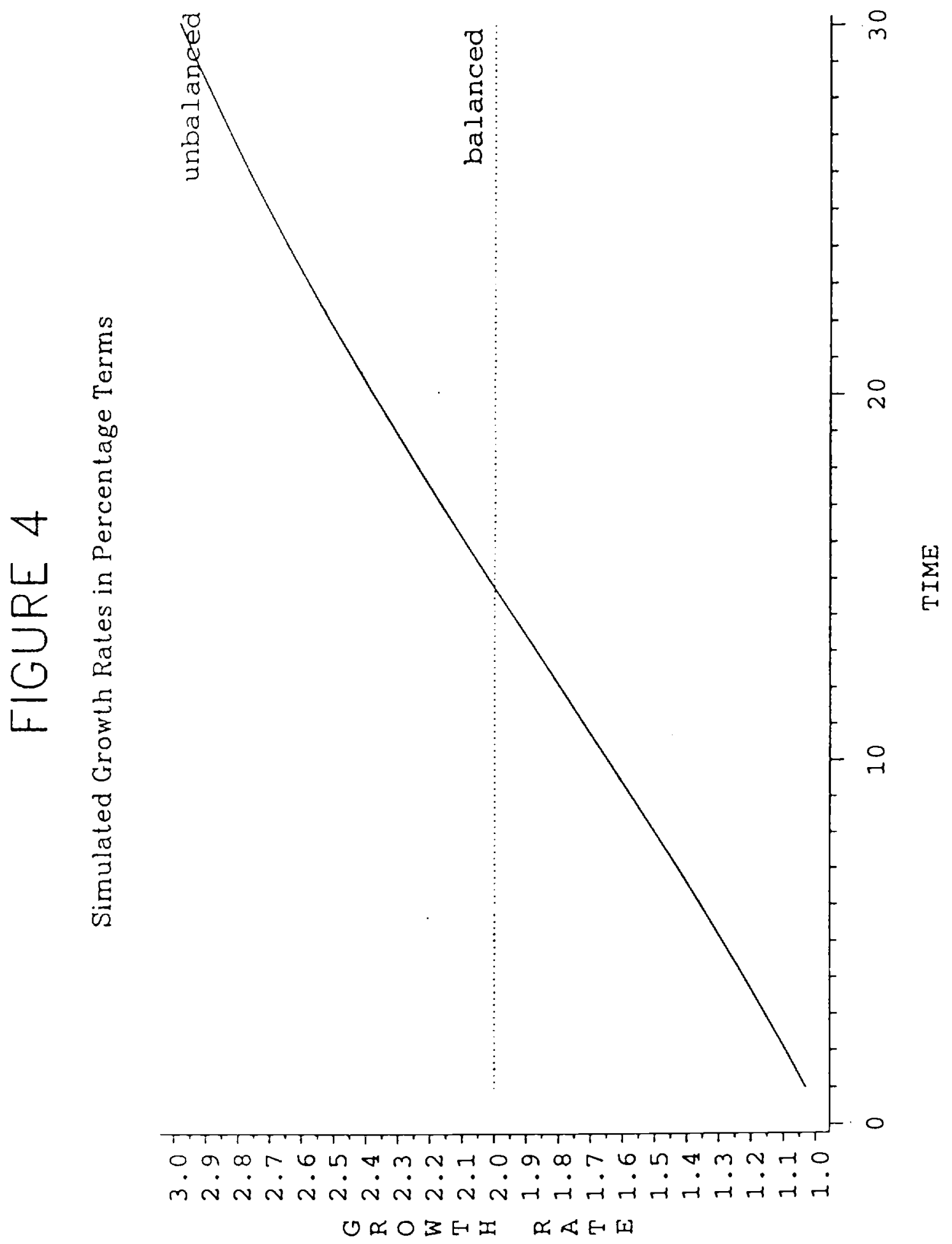




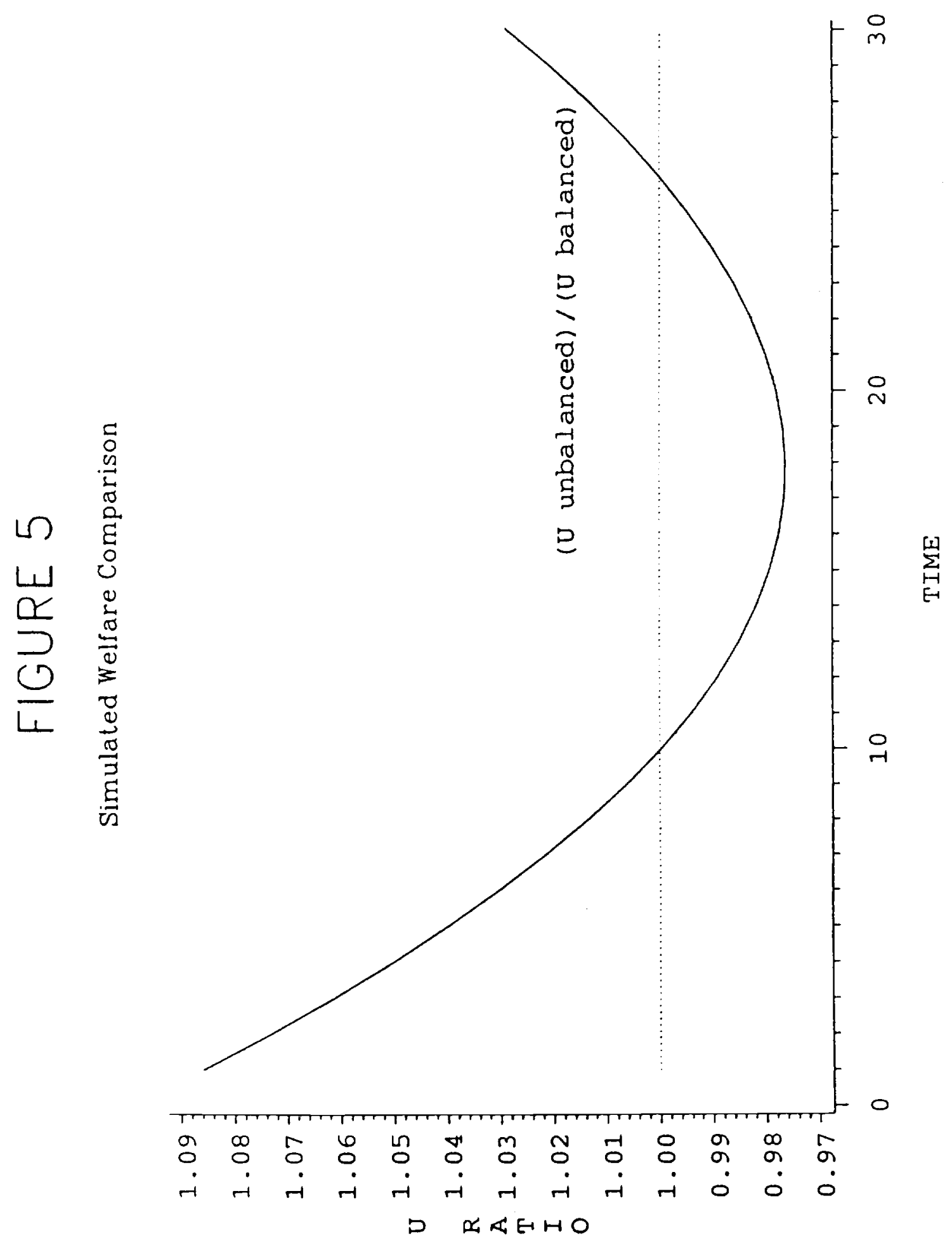




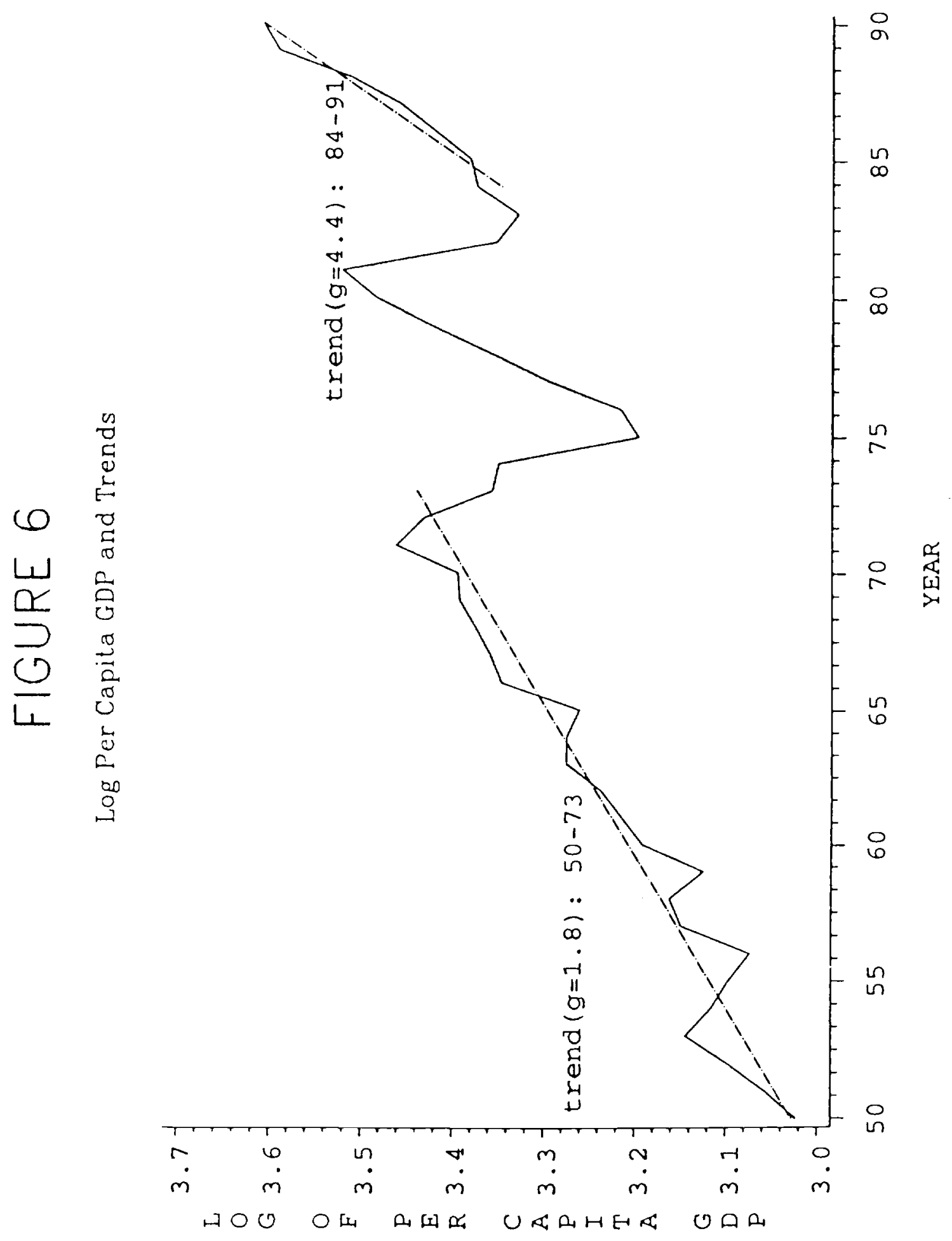




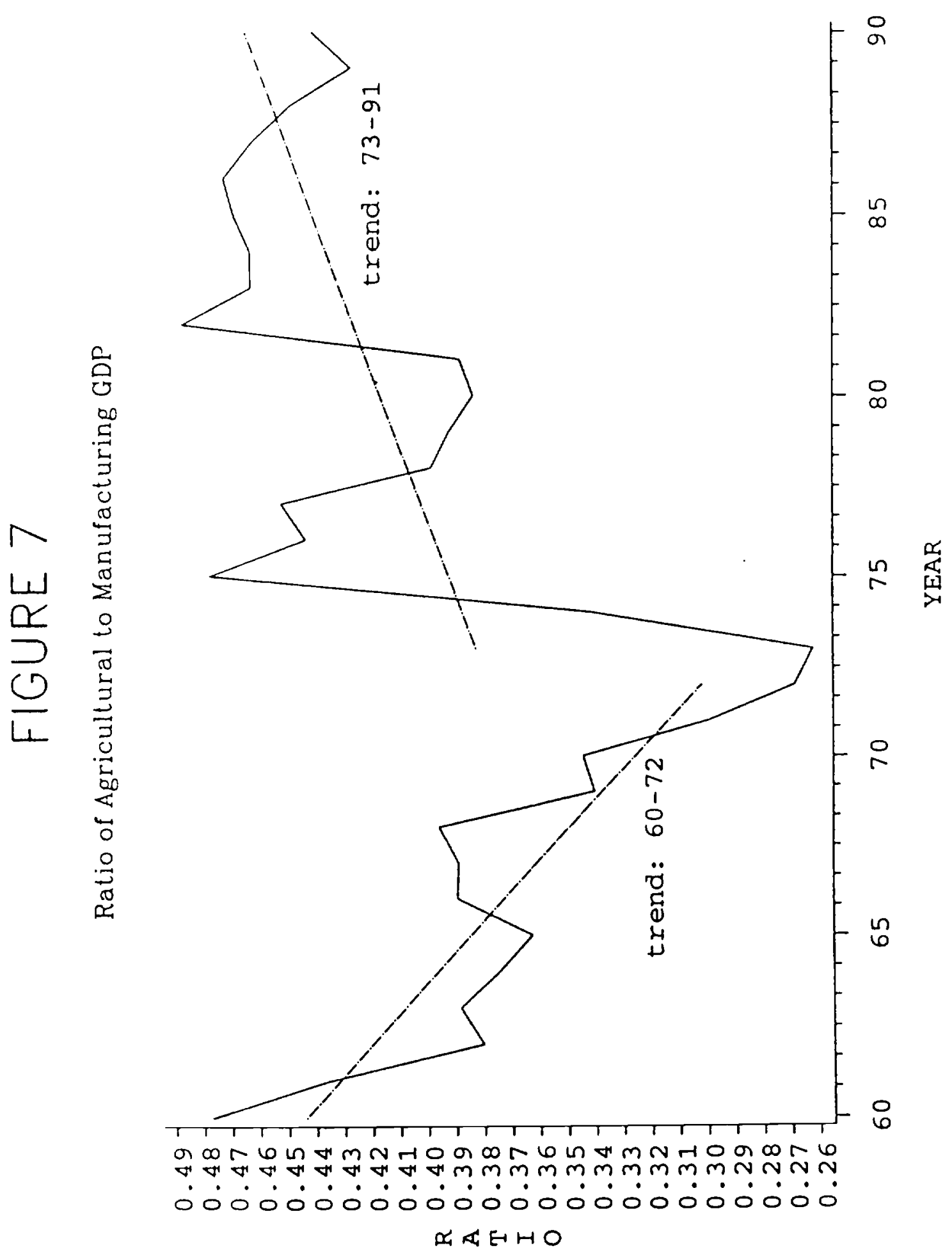




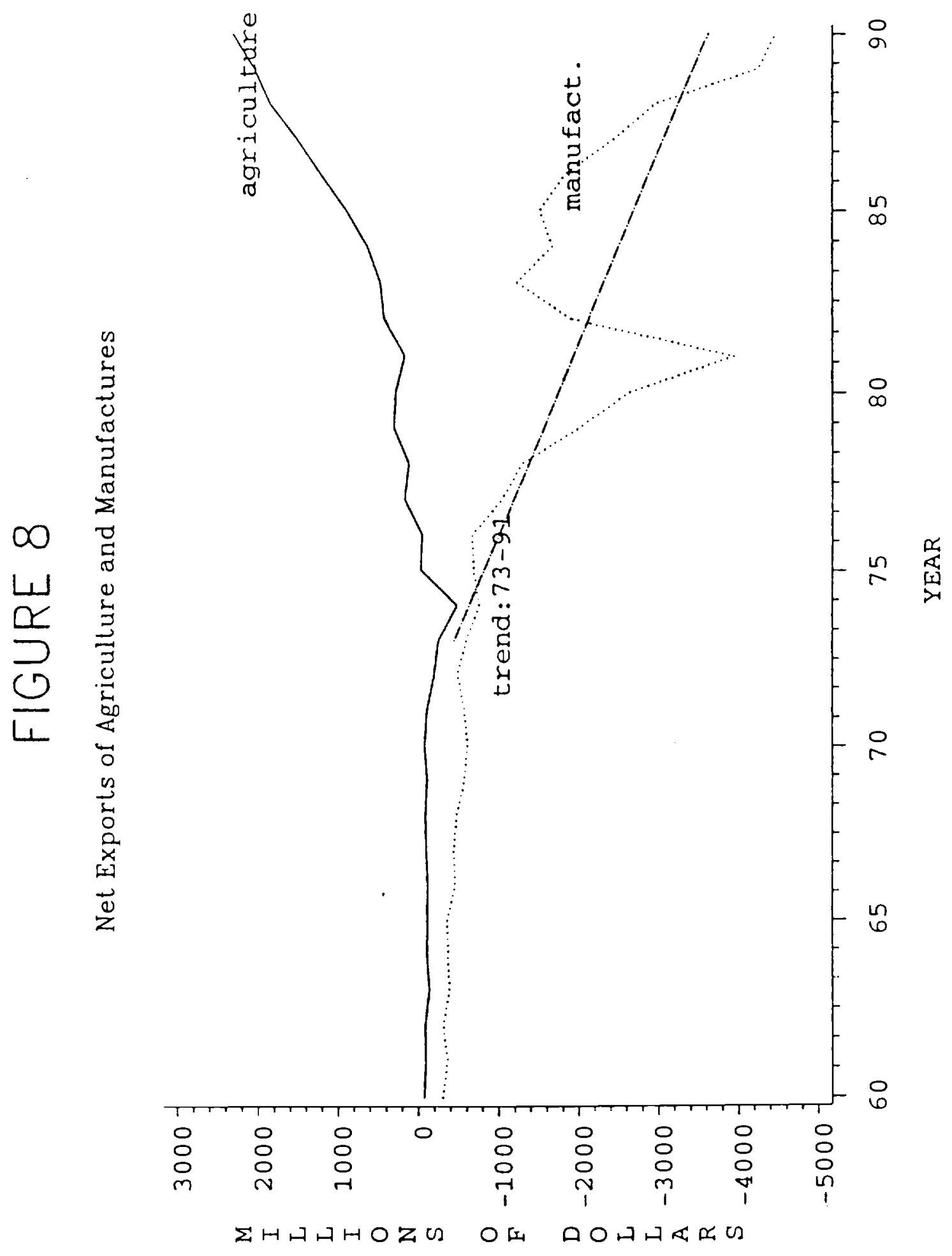




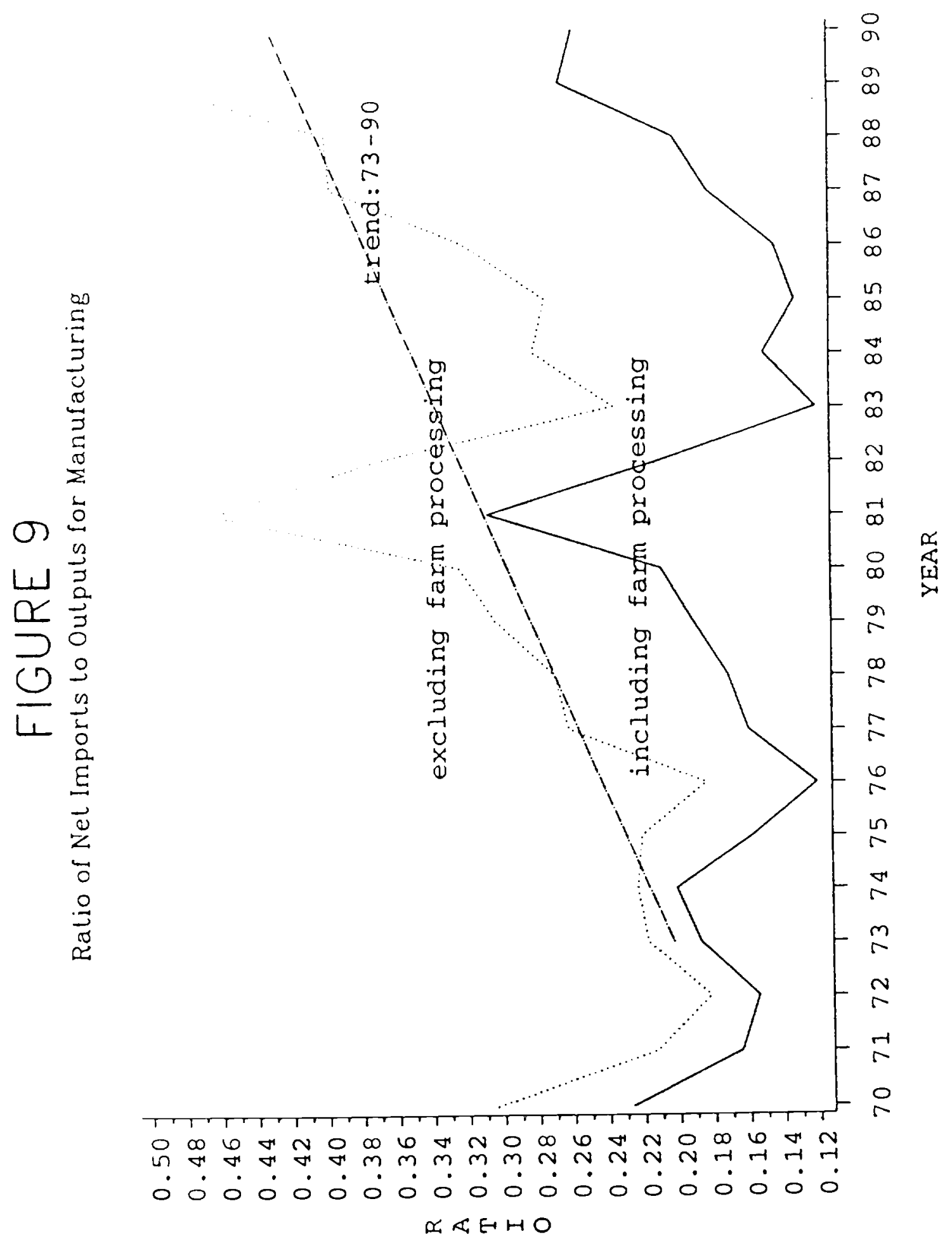




\section{Notes to Figures $6-9$}

Figure 6:

Per capita GDP for 1960-1991 was computed using data for GDP in 1977 Chilean pesos from Economic Commission for Latin America and the Caribbean (ECLAC), based on official data, and population data from version 5 of the Penn World Tables. Per capita GDP for 1950-1959 was computed by extrapolating backwards from 1960 using the per capita GDP growth rates implied by version 5 of the Penn World Tables.

Figure 7:

Source: ECLAC, based on official data.

Figure 8:

Agriculture includes Standard International Trade Classification (SITC) Sections 0, 1, 2, 4 less Divisions 27 and 28. Manufacturing includes SITC Sections 5-8 less

Division 68. Sources are United Nations, Yearbook of International Trade Statistics, various years, and ECLAC, Data Bank on Latin American and Caribbean Foreign Trade (BADECEL).

Figure 9:

Solid line shows manufacturing defined by International Standard Industrial Classification (ISIC) Section 300 less 372 (Non-Ferrous Metals). Dotted line shows manufacturing defined by ISIC 300 less 372, 311 (Food Products), 313 (Beverages), 314 (Tobacco), and 331 (Wood Products, Except Furniture). Source: Joint ECLAC/UNIDO Industry and Technology Division. 